\title{
2-Amino-I,3,4-thiadiazole as a potential scaffold for promising antimicrobial agents
}

This article was published in the following Dove Press journal:

Drug Design, Development and Therapy

\author{
Georgeta Serban ${ }^{1, *}$ \\ Oana Stanasel $2, *$ \\ Eugenia Serban ${ }^{3}$ \\ Sanda Bota ${ }^{2, *}$ \\ 'Pharmaceutical Chemistry \\ Department, Faculty of Medicine \\ and Pharmacy, University of Oradea, \\ Oradea, Romania; ${ }^{2}$ Chemistry \\ Department, Faculty of Sciences, \\ University of Oradea, Oradea, \\ Romania; ${ }^{3}$ Faculty of Environmental \\ Protection, University of Oradea, \\ Oradea, Romania \\ *These authors contributed equally \\ to this work
}

\begin{abstract}
Pathogenic microorganisms are causative agents for different types of serious and even lethal infectious diseases. Despite advancements in medication, bacterial and fungal infections continue to be a growing problem in health care. As more and more bacteria become resistant to antibiotics used in therapy and an increasing number of invasive fungal species become resistant to current antifungal medications, there is considerable interest in the development of new compounds with antimicrobial activity. The compounds containing a heterocyclic ring play an important role among organic compounds with biological activity used as drugs in human and veterinary medicine or as insecticides and pesticides in agriculture. Thiadiazoles belong to the classes of nitrogen-sulfur heterocycles with extensive application as structural units of biologically active molecules and as useful intermediates in medicinal chemistry. The potency of the thiadiazole nucleus is demonstrated by the drugs currently used. 1,3,4-Thiadiazoles and some of their derivatives are extensively studied because of their broad spectrum of pharmacological activities. The aim of this review was to highlight the main antimicrobial properties exhibited by derivatives possessing 2-amino-1,3,4-thiadiazole moiety. Many of the reported 2-amino-1,3,4-thiadiazole derivatives can be considered as lead compounds for drug synthesis, and several of them have demonstrated higher antimicrobial activity in comparison to standard drugs. Furthermore, taking into account the reactivity of the amine group in the derivatization process, 2-amino-1,3,4-thiadiazole moiety may be a good scaffold for future pharmacologically active 1,3,4-thiadiazole derivatives.
\end{abstract}

Keywords: 2 -amino-1,3,4-thiadiazole, antimicrobial activity, antibacterial activity, antifungal activity, antitubercular activity, minimum inhibitory concentration

\section{Introduction}

Heterocyclic compounds play an important role among organic compounds with biological activity used as drugs in human and veterinary medicine or as insecticides and pesticides in agriculture. Chemical rings, which are present in many marketed drugs, may possess pharmacological properties or may serve as a platform for the pharmacophoric groups which will interact with the receptors. ${ }^{1}$

Thiadiazoles belong to the classes of nitrogen-sulfur containing heterocycles with extensive application as structural units of biologically active molecules and as useful intermediates in medicinal chemistry. There are several isomers of the thiadiazole ring (eg, 1,2,3-thiadiazole, 1,2,4-thiadiazole, 1,2,5-thiadiazole and 1,3,4-thiadiazole; Figure 1). During the past years, substituted 1,3,4-thiadiazole derivatives have received significant attention and have been increasingly investigated due to their broad spectrum of pharmacological properties. It is supposed that 1,3,4-thiadiazole derivatives exhibit various biological activities due to the presence of $=\mathrm{N}-\mathrm{C}-\mathrm{S}-$ moiety. ${ }^{2}$ Other authors assume that the biological activities of 1,3,4-thiadiazole derivatives are due to
Correspondence: Georgeta Serban Pharmaceutical Chemistry Department, Faculty of Medicine and Pharmacy, University of Oradea, 29 Nicolae Jiga, 4I0028 Oradea, Romania Email getaserban_2000@yahoo.com

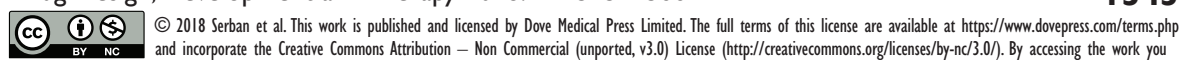

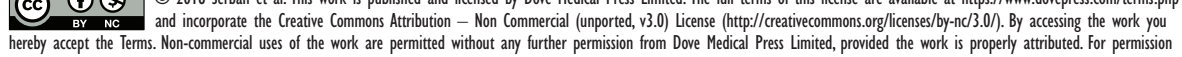

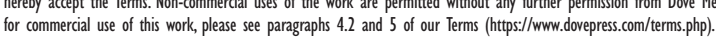




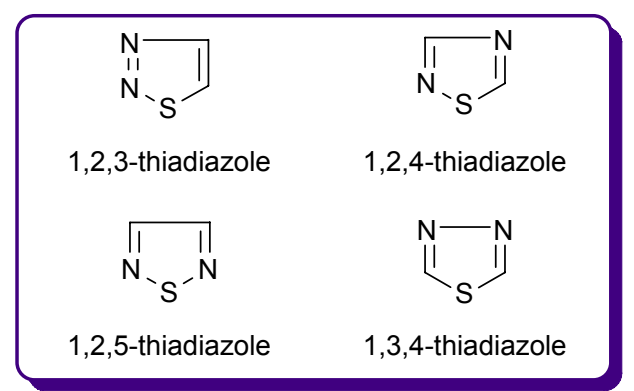

Figure I Natural isomers of the thiadiazole ring.

the strong aromaticity of the ring, which also provides great in vivo stability to this five-membered ring system and low toxicity for higher vertebrates, including human beings. ${ }^{3}$

There are some studies that show the importance of isosterism for the pharmacological profile of a compound. According to these studies, 1,2,4-thiadiazole is the bioisostere of pyrimidine, while the 1,3,4-thiadiazole is the bioisostere of pyridazine through the substitution of $-\mathrm{CH}=\mathrm{CH}-$ by $-\mathrm{S}-$ (Figure 2). ${ }^{4,5}$ The thiadiazole ring is also a bioisostere of oxadiazole, oxazole, thiazole and benzene ring. ${ }^{4,6}$ The bioisosteric replacement of a ring with another ring might lead to compounds with increased lipophilicity and improved biological properties. The thiadiazole derivatives, due to the presence of sulfur atom that gives high liposolubility, show oral absorption and good cell permeability leading to a good bioavailability. In addition, substitution of a homocyclic ring with a heterocycle makes the synthesis of different analogs possible which interact more with the receptors. ${ }^{4,7,8}$

Considering the high prevalence of pyrimidine derivatives in nature and also the presence of pyridazine ring in compounds possessing pharmacological activities (eg, the antidepressant, minaprine; GABA-A antagonist, gabazine; nonsteroidal antiinflammatory drug, emorfazone and the antibacterial cephalosporin, cefozopran), the potential of thiadiazole derivatives to exhibit biological activities is very high..$^{9-11}$

Moreover, 1,3,4-thiadiazole derivatives can produce mesoionic salts (Figure 3). Mesoionic system contains a pentatomic heterocyclic ring which possesses a sextet of

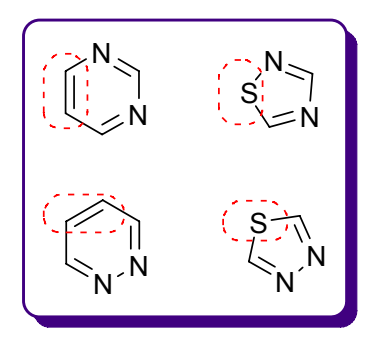

Figure 2 Isosterism between the six-membered diazaheterocycles and thiadiazole derivatives.

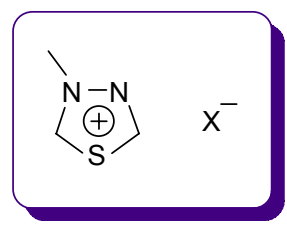

Figure 3 Chemical structure of the mesoionic salt derivatives formed by I,3,4thiadiazole compounds.

$p$ and $\pi$ electrons and positive charge counterbalanced by formal negative charge. Despite their internal charges, the mesoionic compounds are neutral and able to cross cellular membranes, and this contributes to the good cell permeability of 1,3,4-thiadiazole derivatives. The mesoionic nature of 1,3,4-thiadiazoles enables these compounds to interact strongly with biomolecules (eg, DNA and proteins)., ${ }^{4}$

The biological importance of 1,3,4-thiadiazole derivatives has been reported following the discovery of heterocyclic sulfonamides as reasonable antimicrobial agents (eg, sulfathiazole 1; Winthrop Chemical Company, NY, USA, 1940). ${ }^{13,14}$ In analogy to sulfathiazole, other sulfonamides showing similar activity such as "sulfamethizole" 2 (4-amino$N$-(5-methyl-1,3,4-thiadiazol-2-yl)benzene sulfonamide, Rufol [Urgo Laboratories, Chenove, France]) $)^{15,16}$ or "sulfaethidole" 3 (4-amino- $N$-[5-ethyl-1,3,4-thiadiazol-2-yl]benzene sulfonamide, Globucid [Schering, Berlin, Germany]) ${ }^{17}$ were prepared. Except sulfathiazole that is still used in the treatment of Haemophilus vaginalis vaginitis, ${ }^{18}$ sulfamethizole and sulfaethidole currently possess only historical importance.<smiles>Nc1ccc(S(=O)(=O)Nc2nccs2)cc1</smiles><smiles>Cc1nnc(NS(=O)(=O)c2ccc(N)cc2)s1</smiles><smiles>CCc1nnc(NS(=O)(=O)c2ccc(N)cc2)s1</smiles> 
The synthesis of "acetazolamide" 4 (5-acetylamino-1,3,4thiadiazol-2-sulfonamide) by Roblin and Clapp ${ }^{19}$ (Lederle Laboratories, Pearl River, NY, USA) as carbonic anhydrase inhibitor reoriented the researchers to sulfonamides bearing 1,3,4-thiadiazole ring. Acetazolamide was marketed as Diamox (Lederle Laboratories, American Cyanamid Company, Pearl River, NY, USA) in $1954 .{ }^{19-21}$ Although its use as a diuretic is limited by systemic acidosis as a side effect, ${ }^{22}$ acetazolamide is currently a good antiglaucoma agent. Its methylated derivative, "methazolamide" 5 (Neptazane [Fera Pharmaceuticals, Locust Valley, NY, USA]), is a more potent carbonic anhydrase inhibitor and displays diuretic, antiglaucoma and potential antineoplastic activity. ${ }^{23}$<smiles>CC(=O)Nc1nnc(S(N)(=O)=O)s1</smiles>
4
Olsen et $\mathrm{al}^{24}$ discovered the cytostatic properties of "2-amino-1,3,4-thiadiazole," having as a result many publications that launched new 1,3,4-thiadiazole derivatives with potential anticancer activity.

The synthetic studies concerning the therapy of parasitic infections gave "megazol" 6 (2-amino-5-[1-methyl-5-nitro1H-2-imidazolyl]-1,3,4-thiadiazole, CL 64855), ${ }^{25}$ a nitroimidazole extremely active in experimental infections caused by Trypanosoma cruzi and Trypanosoma brucei as well as drug-resistant forms of trypanosomiasis. Megazol has been found to be the best-known anti-trypanosomal candidate for the treatment of sleeping sickness in Africa and Chagas disease in South America. However, due to the high toxicity (mutagenic and genotoxic properties), its development has been postponed, but it serves as a lead compound for the development of new anti-trypanosomal agents. ${ }^{26-31}$

1,3,4-Thiadiazole ring is the constitutive part of some cephalosporins and cephamycins that showed high in vitro activity against both Gram-positive and Gram-negative bacteria. A good example is "cefazolin" 7, a first-generation cephalosporin which has been used worldwide since the early 1970s (GlaxoSmithKline plc, London, UK; Ancef). ${ }^{32,33}$

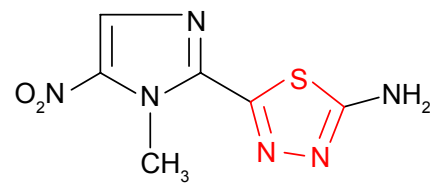

6

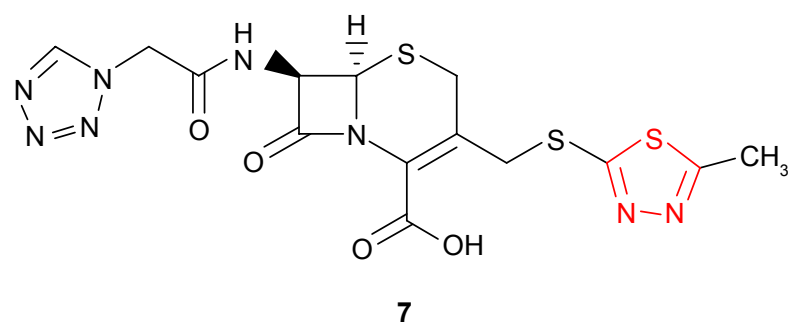

Cefazolin is a semisynthetic cephalosporin for parenteral treatment of bacterial infections in various organs, including septicemia. ${ }^{32-34}$ The treatment of infections with penicillins and cephalosporins failed many times due to the methicillinresistant Staphylococcus aureus (MRSA) strains. As a result, the use of glycopeptide antibiotics (eg, vancomycin and teicoplanin) was increased. During the past years, vancomycin-resistant strains were found. To prevent the development of drug resistance, several clinical studies to compare the efficacy of cefazolin vs teicoplanin and vancomycin, respectively, were initiated. The results proved that, for the prevention of surgical-site infections, cefazolin might be the first-line medication. ${ }^{34-38}$

1,3,4-Thiadiazole ring is an important scaffold known to be associated with several biological activities including antimicrobial, ${ }^{39-41}$ antituberculosis, ${ }^{42}$ antiviral, ${ }^{43}$ analgesic, ${ }^{44}$ antidepressant and anxiolytic, ${ }^{45}$ antihypertensive,${ }^{46}$ anticonvulsant, anti-inflammatory, ${ }^{47,48}$ local anesthetic ${ }^{49}$ and kinesin inhibitors. ${ }^{50,51}$ During the past 2 decades, the number of scientific publications concerning the synthesis and biological investigation of 1,3,4-thiadiazoles has considerably increased. In addition, the amine derivatives of 1,3,4-thiadiazole are also studied. Aliphatic and aromatic amines are important moieties in many natural or synthetic biologically active compounds. Naturally occurring amines include alkaloids such as ephedrine and pseudoephedrine, which are present in several drug combinations, and catecholamine neurotransmitters (dopamine, epinephrine and norepinephrine) are essential for the proper activity of the nervous system and valuable drugs used in therapy. It is not surprising that more than $75 \%$ of drug candidates contain free or substituted amine groups..$^{52,53}$

The cytostatic properties of 2-amino-1,3,4-thiadiazole and the anti-trypanosomal properties of megazol are evidence of the biological potential of 2-amino-1,3,4-thiadiazole moiety. The aim of this review was to highlight the main antimicrobial properties exhibited by derivatives possessing 2-amino-1,3,4-thiadiazole moiety. Furthermore, taking into account the reactivity of the amine group in the derivatization process, 2-amino-1,3,4-thiadiazole moiety 
may be an excellent scaffold for future pharmacologically active 1,3,4-thiadiazole derivatives. The covalent bonding of biologically active compounds with similar effect but acting by different mechanisms could lead, by synergism, to compounds with improved activity and less toxicity. ${ }^{54}$ Some of the derivatives included in this review have the 1,3,4-thiadiazole ring linked to different homocyclic cores but many of them are bis- or polyheterocyclic compounds bearing the thiadiazole moiety linked to other heterocyclic rings. In addition, this review provides some information about structure-activity relationship (SAR) studies.

\section{Antimicrobial activities associated with 2-amino-I,3,4-thiadiazole system}

Pathogenic microorganisms are causative agents for different types of diseases such as upper and lower respiratory tract infections, typhoid fever, gastrointestinal infections, gynecological infections, sexually transmitted diseases, urinary tract infections, bacterial meningitis, osteomyelitis and malaria and also for severe diseases such as tuberculosis, influenza, syphilis and acquired immunodeficiency syndrome (AIDS). Taking into account that infectious diseases affect millions of people and cause many deaths worldwide, it can be said that anti-infective agents have saved more lives than other classes of drugs. ${ }^{55}$

\section{Antibacterial and antifungal activities}

The antimicrobial chemotherapy is the way to combat infections through the pharmacological effects of the drugs used. Antimicrobial agents have specific toxic action on pathogenic organisms. Since the introduction of the first antibiotic (penicillin, 1942) into medical practice, there has been an ongoing race between scientists and pathogenic bacteria. ${ }^{56}$ In the struggle for existence, the microorganisms constantly adapt by selecting higher invasive and more resistant strains. Despite the large number of antibiotics and chemotherapeutics available for medical use, the bacterial infections have dramatically increased due to bacterial resistance to antimicrobial drugs. On the other hand, the spread of HIV infection combined with the increased use of powerful immunosuppressive drugs for cancer therapy and organ transplants led to increased incidence of fungal infections among immunocompromised patients. Although most fungal infections were superficial in the past, the incidence of systemic fungal infections has currently increased. ${ }^{55,57}$ The gravity of bacterial and fungal infections became a major worldwide problem, and the World Health Organization chose the antimicrobial resistance as the theme of the 2011 World Health Day. Due to the occurrence of bacterial resistance (eg, MRSA that is resistant to many antibiotics), researchers are in a continuous effort to counteract infections by synthesizing new effective antibacterial and antifungal agents. ${ }^{56,58-60}$

Thiadiazole ring acts as a pharmacophore. It is also a bioisostere of the thiazole ring included in the third- and fourthgeneration cephalosporins, and this observation makes it possible to use it in the synthesis of antimicrobial agents. ${ }^{61}$

Upadhyay and Mishra ${ }^{62}$ synthesized the 5-(4-substituted phenyl)-1,3,4-thiadiazol-2-amine derivatives 8 and performed in vitro antibacterial activity against $S$. aureus, Bacillus subtilis, Escherichia coli and Pseudomonas aeruginosa and antifungal activity against Aspergillus niger and Candida albicans by disk diffusion technique. Fluorinated and chlorinated compounds $\mathbf{8 a}$ and $\mathbf{8 b}$ showed good inhibitory effects (inhibition between $81 \%$ and $91 \%$ ) with minimum inhibitory concentration (MIC) values of $20-28 \mu \mathrm{g} / \mathrm{mL}$ (controlled to ciprofloxacin, $\mathrm{MIC}=18-20 \mu \mathrm{g} / \mathrm{mL}$ ) for $S$. aureus and B. subtilis. In addition, halogenated compounds 8a-c and hydroxyl derivative $\mathbf{8 d}$ showed moderate inhibitory effects (inhibition between $58 \%$ and $79 \%$ ) with MIC values of $24-40 \mu \mathrm{g} / \mathrm{mL}$ (controlled to ciprofloxacin, $\mathrm{MIC}=20-24 \mu \mathrm{g} / \mathrm{mL}$ ) for $E$. coli and $P$. aeruginosa. Significant antifungal activity against A. niger and C. albicans was exhibited by derivatives $\mathbf{8 d}$ and 8e bearing oxygenated substituents at phenyl ring (inhibition between $58 \%$ and $66 \%$ and $\mathrm{MIC}=32-42 \mu \mathrm{g} / \mathrm{mL}$ compared to fluconazole, $\mathrm{MIC}=24-26 \mu \mathrm{g} / \mathrm{mL})$. It appears that the halogen attached to the phenyl-1,3,4-thiadiazol moieties increases the antibacterial activity with preference against Gram-positive bacteria, while the oxygenated substituents impart antifungal activity.

A new series of 4-amino-2- $\{5-[(4-$ substituted phenyl) amino]-1,3,4-thiadiazol-2-yl\} phenols 9 was synthesized, and the compounds were in vitro evaluated for their antimicrobial activity. Among the series 9, the chlorinated and fluorinated derivatives 9d-f exhibited good antibacterial activity against $S$. aureus and $E$. coli strains and antifungal activity against A. niger with MIC values of $25 \mu \mathrm{g} / \mathrm{mL}^{63}$

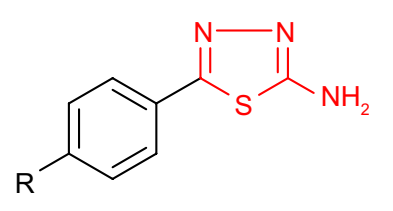

$\mathrm{R}=\mathrm{F}(\mathrm{a}) ; \mathrm{Cl}(\mathrm{b}) ; \mathrm{Br}(\mathrm{c})$;

$\mathrm{OH}(\mathrm{d}) ; \mathrm{OCH}_{3}(\mathrm{e})$

8 


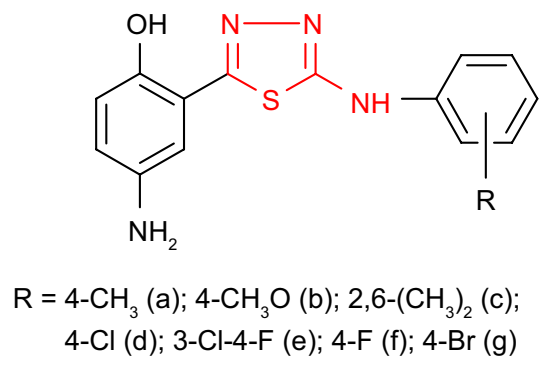

9

Other fluorinated compounds incorporating 1,3, 4-thiadiazole ring and the diflunisal (a nonsteroidal antiinflammatory drug) structure were tested for antimicrobial activity using microwell dilution assay and MIC agar dilution assay. 5-(2',4'-Difluoro-4-hydroxybiphenyl-5-yl)phenylamino-1,3,4-thiadiazole $\mathbf{1 0}$ showed activity against E. coli and Streptococcus pyogenes at a concentration of $31.25 \mu \mathrm{g} / \mathrm{mL}$ (inhibition zone of $16-18 \mathrm{~mm}$ ), two times greater than that observed for the control drug, ofloxacin (MIC $=62.5 \mu \mathrm{g} / \mathrm{mL}$ ). In addition, another standard drug, cefepime, was found less active against the bacteria mentioned earlier. ${ }^{64}$

Kadi et a $1^{54,65}$ have synthesized new 2-(1-adamantylamino)5 -substituted-1,3,4-thiadiazole derivatives 11. The investigation of antimicrobial screening of the synthesized compounds revealed that the best antibacterial activity was exhibited by the $p$-chlorophenyl 11c and $p$-nitrophenyl 11e derivatives against Gram-positive microorganisms such as B. subtilis and $S$. aureus. Only $p$-nitrophenyl derivative 11e showed good activity against the Gram-negative bacteria E. coli in comparison to the reference drug, ampicillin. SAR studies have shown that the introduction of another adamantyl moiety on C-5 of thiadiazole ring increased the antifungal activity against $C$. albicans.

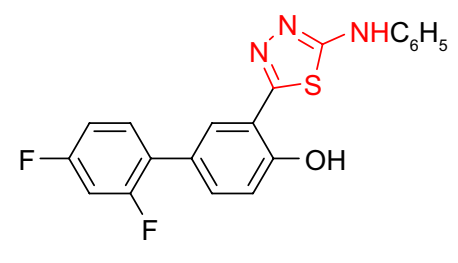

10

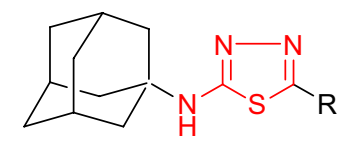

$\mathrm{R}=\mathrm{C}_{6} \mathrm{H}_{5}(\mathrm{a}) ; 4-\mathrm{FC}_{6} \mathrm{H}_{4}(\mathrm{~b}) ; 4-\mathrm{ClC}_{6} \mathrm{H}_{4}(\mathrm{c}) ;$
4- $\mathrm{BrC}_{6} \mathrm{H}_{4}(\mathrm{~d}) ; 4-\mathrm{NO}_{2} \mathrm{C}_{6} \mathrm{H}_{4}(\mathrm{e}) ; 1$-adamantyl (f)
$\mathbf{1 1}$
The in vitro antimicrobial activity of some new 1,3,4thiadiazole derivatives such as $\mathbf{1 2}$ having a D,L-methionine moiety has been evaluated against several bacterial strains by Pintilie et al. ${ }^{66}$ From the findings, the authors revealed that 1,3,4-thiadiazole derivatives have good activity against Bacillus anthracis and Bacillus cereus, the most active compound 12c possessing a 4-methylphenyl moiety on the heterocyclic ring. The compounds showed a very weak activity against $S$. aureus and $E$. coli strains and were inactive against Sarcina lutea strain. The antimicrobial activity of some thioethers derived from 2-amino-5-mercapto-1,3,4thiadiazole was found to be dependent on the substitution at the mercapto group. Even though all the tested compounds showed moderate antibacterial activity against Gram-positive and Gram-negative bacterial strains and moderate to good antifungal activity against $C$. albicans, the findings revealed that the antimicrobial activity was improved by the introduction of a 1-arylethanone moiety at the mercapto group. The unsubstituted and halogenated aryl derivatives $\mathbf{1 3}$ proved to be the most active compounds against Salmonella typhimurium and C. albicans. ${ }^{67}$

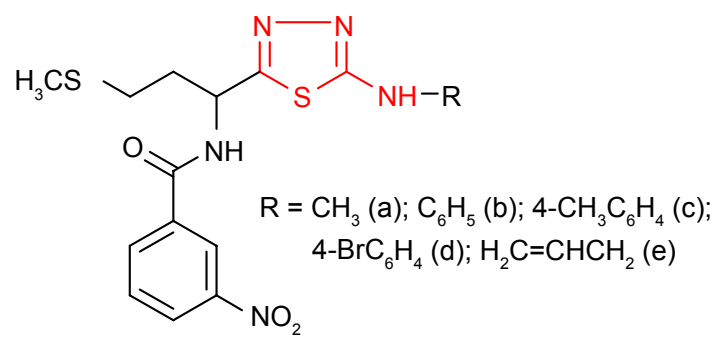

12<smiles>Nc1nnc(SCC(=O)Br)s1</smiles>

$\mathrm{Ar}=$ naphtyl; $4-\mathrm{ClC}_{6} \mathrm{H}_{4} ; \mathrm{C}_{6} \mathrm{H}_{5}$

13

A series of 5-substituted 2-(2,4-dihydroxyphenyl)1,3,4-thiadiazole derivatives such as $\mathbf{1 4}$ synthesized by Matysiak and Malinski ${ }^{68}$ has been evaluated for antifungal activity against $C$. albicans and Candida nonalbicans species. Many derivatives exhibited higher activity against $C$. nonalbicans species compared to standard drugs, itraconazole ( $\mathrm{MIC}=85.6 \mu \mathrm{g} / \mathrm{mL}$ ) and fluconazole (MIC $=120.8 \mu \mathrm{g} / \mathrm{mL}$ ), 2,4-dichlorophenylamino derivative 14d $(\mathrm{MIC}=37.8 \mu \mathrm{g} / \mathrm{mL})$ and morpholinoethylamino 
derivative 14f $(\mathrm{MIC}=34.4 \mu \mathrm{g} / \mathrm{mL})$ being the most active compounds. The aminoderivatives substituted with the methyl, phenyl, halogenophenyl, ethoxyphenyl and morpholinoalkyl groups showed higher antifungal activity against $C$. albicans strains. For some of them, such as phenylamino derivative 14b $(\mathrm{MIC}=36.3 \mu \mathrm{g} / \mathrm{mL})$ and 2,4-dichlorophenylamino derivative $14 \mathbf{d}(\mathrm{MIC}=32.6 \mu \mathrm{g} / \mathrm{mL})$, an activity higher than that of itraconazole ( $\mathrm{MIC}=47.5 \mu \mathrm{g} / \mathrm{mL}$ ) was observed. A number of 2-amino-1,3,4-thiadiazoles substituted at C-5 of thiadiazole ring with the phenyl or phenol group showed moderate to significant antibacterial and antifungal activities against Gram-positive bacteria ( $S$. aureus and B. cereus), Gram-negative bacteria (E. coli and $P$. aeruginosa) and fungal strains (A. niger and Aspergillus fumigatus) compared to standard drugs, streptomycin and fluconazole. The compounds 15 possessing the $p$-nitroaniline moiety showed the most promising antibacterial and antifungal properties. ${ }^{69}$<smiles>[R]Nc1nnc(-c2ccc(O)cc2O)s1</smiles>

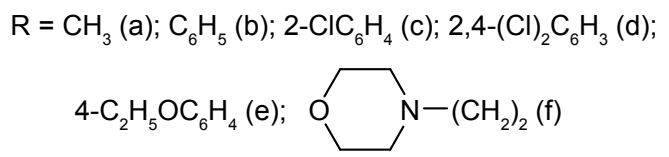

14<smiles>[R]c1ccccc1-c1nnc(NCNc2ccc([N+](=O)[O-])cc2)s1</smiles>

$\mathrm{R}=\mathrm{H}, \mathrm{OH}$

15

Some nitrophenoxymethyl-1,3,4-thiadiazole derivatives such as $\mathbf{1 6}$ synthesized by Shah et $\mathrm{al}^{70}$ were evaluated for antimicrobial activity. The introduction of the nitro group significantly increased the antibacterial activity against $S$. aureus, the studied compounds exhibiting comparable activity to standard drugs, chloramphenicol and ampicillin. In comparison, the acetamidophenoxymethyl1,3,4-thiadiazole derivatives 17 exhibited moderate antibacterial activities against $B$. subtilis. The introduction of $p$-tolyl substituent (compound 17b) at the amine group of 1,3,4-thiadiazole ring significantly increased the activity. ${ }^{71}$

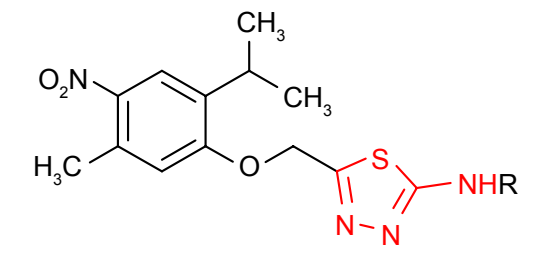

$$
\begin{gathered}
\mathrm{R}=2,6-\left(\mathrm{CH}_{3}\right)_{2} \mathrm{C}_{6} \mathrm{H}_{3} ; 4-\mathrm{CH}_{3} \mathrm{OC}_{6} \mathrm{H}_{4} ; 3-\mathrm{CH}_{3} \mathrm{C}_{6} \mathrm{H}_{4} \\
16
\end{gathered}
$$

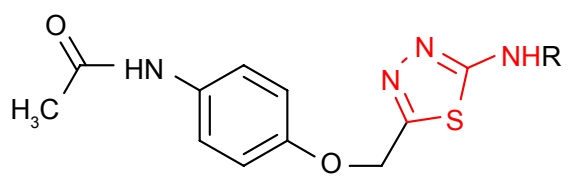

$\mathrm{R}=\mathrm{C}_{6} \mathrm{H}_{5}(\mathrm{a}) ; 4-\mathrm{CH}_{3} \mathrm{C}_{6} \mathrm{H}_{4}(\mathrm{~b}) ; 4-\mathrm{CH}_{3} \mathrm{OC}_{6} \mathrm{H}_{4}$ (c)

17

Having 5-(4-chlorophenylamino)-2-mercapto-1,3,4thiadiazole as starting material, Sah et $\mathrm{al}^{72}$ have synthesized the Mannich base which was converted to the corresponding formazans with aromatic, benzenesulfonic acid or sulfonamide moiety. Among the synthesized compounds, the aromatic formazans $\mathbf{1 8}$ were the most active compounds showing good activity (zone of inhibition of 15-19 mm) against Salmonella typhi strain (compound 18a) and E. coli strain (compound $\mathbf{1 8 b}$ ) at the concentration of $500 \mu \mathrm{g} / \mathrm{disk}$. The same compounds showed good antifungal activity against $A$. niger and/or Penicillium sp. and only moderate activity against $C$. albicans.

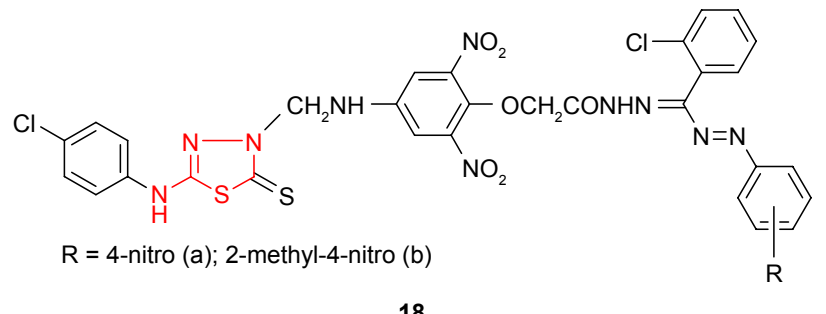

Dogan et $\mathrm{al}^{73}$ have examined the effect of various substitutions at the amine group of 2-amino-5-(3-hydroxy-2naphthyl)-1,3,4-thiadiazole on antimicrobial activity against different bacterial and fungal strains. Among the series, the $p$-chlorophenyl derivative $\mathbf{1 9}$ was marginally active against $S$. aureus (MIC value of $62.5 \mu \mathrm{g} / \mathrm{mL}$ ), and it may be considered for the development of new antibacterial agents.

Insertion of a long alkenyl/hydroxyalkenyl chain to the fifth position of 1,3,4-thiadiazole ring is a useful tool in the 
synthesis of biologically active compounds. Such 5-alkenyl/ hydroxyalkenyl-2-phenylamine-1,3,4-thiadiazoles 20 showed good antibacterial activity against $E$. coli, $S$. aureus, $P$. aeruginosa, S. pyogenes and Klebsiella pneumoniae and moderate to good antifungal activity against $C$. albicans, A. fumigatus, Penicillium marneffei and Trichophyton mentagrophytes. Antimicrobial activity data indicated that derivatives 20a and 20b having a hydroxyalkenyl chain substituent at C-5 are good antibacterial agents with almost equal potency against $K$. pneumoniae as the reference drug, chloramphenicol. The position of the hydroxyl group did not have a significant influence on the pharmacological effect. The alkenyl derivatives such as $\mathbf{2 0 c}$ were found to be potent antifungal agents compared to standard drug, griseofulvin. ${ }^{74}$<smiles>Oc1cc2ccccc2cc1-c1nnc(Nc2ccc(Cl)cc2)s1</smiles>

19

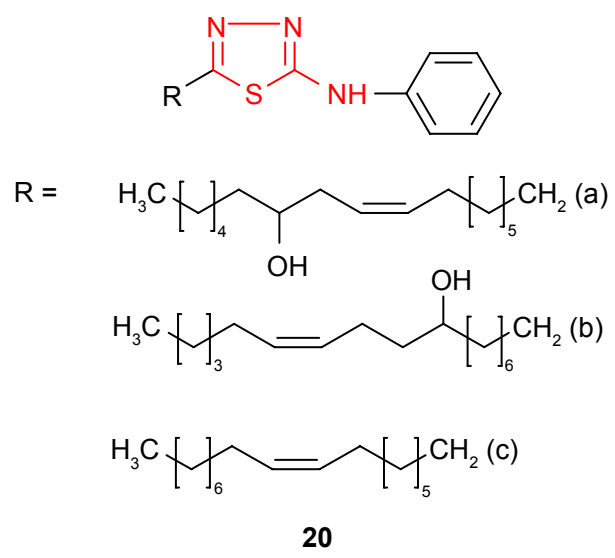

2-Amino-5-R-1,3,4-thiadiazole derivatives have also been investigated for their ability as complexation agents to obtain compounds with enhanced biological properties due to the presence of metal ions. Thus, 5-(2-aminoethyl)-2-amino1,3,4-thiadiazole 21 and its $\mathrm{Cu}$ (II) and $\mathrm{Ni}$ (II) complexes 22a-b were reported by Barboiu et al. ${ }^{75}$ The antifungal activity of the ligand and its metal complexes against two Aspergillus species and C. albicans was investigated. Compared to antifungal drug, clotrimazole, the ligand was much less active, while the metal complexes showed an increased antifungal activity. The most active compound, $\mathrm{Cu}$ (II) complex 22a, was almost as effective as clotrimazole against $A$. niger and more effective against Aspergillus flavus. Obaleye et $\mathrm{al}^{76}$ have synthesized 2,5-diamino-1,3,4-thiadiazole $\mathbf{2 3}$ as a bioactive ligand and its metal complexes with biologically important ions, such as $\mathrm{Co}(\mathrm{II}), \mathrm{Ni}(\mathrm{II})$ and $\mathrm{Cu}(\mathrm{II})$. The ligand behaved as tridentate neutral ligand which coordinated to the metal ions via sulfur and nitrogen of the amines giving solid chelates with general formulae $\left[\left(\mathrm{ML}_{2}\right) \mathrm{Cl}_{2}\right]$ and octahedral geometric structures. The in vitro antimicrobial study of the ligand and its metal complexes showed the antibacterial activity of the tested compounds and no antifungal activity against $A$. niger and Penicillium sp. The most sensitive microorganism to ligand and its metal complexes was Neisseria gonorrhoeae. The metal complexes showed comparable or greater activity against some of the tested microorganisms compared to the ligand. S. typhi, Shigella sp. and P. aeruginosa were more sensitive to the metal complexes than $S$. aureus, Klebsiella sp. and E. coli. In addition, the metal complexes did not show toxicity against the activity of some kidney, liver and serum enzymes, making these compounds promising candidates for antibacterial treatment.

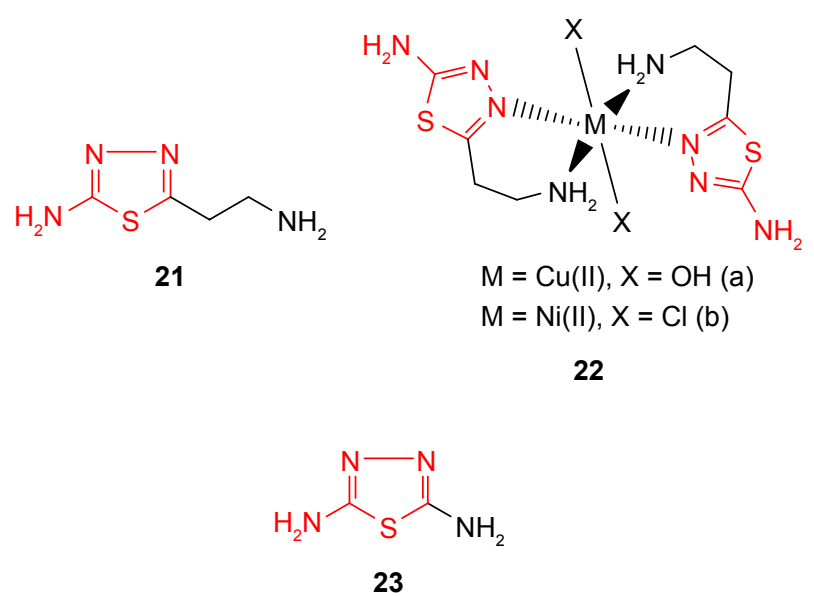

Taking into account that the presence of a heterocyclic ring increases the probability of antimicrobial properties of a compound, bis 1,3,4-thiadiazole derivatives such as $\mathbf{2 4}$ have been synthesized from various dicarboxylic acids and were investigated for in vitro antibacterial and antifungal activities. The results showed that the tested compounds exhibited comparable antimicrobial activity with the standard antibiotics such as ciprofloxacin and griseofulvin, the most active compound being the methyl derivative $(n=1) \cdot{ }^{77}$ Moreover, Salimon et $\mathrm{al}^{41}$ described the synthesis of 2,5-di-[5-amino-1,3,4-thiadiazol2-thiomethyl]-1,3,4-thiadiazole $\mathbf{2 5}$ through the reaction of 2,5-dimercapto-1,3,4-thiadiazole with chloroacetic acid and 
thiosemicarbazide. The antimicrobial screening revealed that the tris-1,3,4-thiadiazole derivative displayed good antimicrobial activity against the Gram-positive bacteria $S$. aureus and Corynebacterium diphtheriae and yeasts such as Saccharomyces cerevisiae and weak activity against Gram-negative bacteria. Other tris-2,5-disubstituted 1,3,4-thiadiazole derivatives such as $\mathbf{2 6}$ synthesized by Rezki et al ${ }^{78}$ showed good antibacterial activity against Gram-positive (Streptococcus pneumoniae, B. subtilis, S. aureus) and Gram-negative bacteria ( $P$. aeruginosa, E. coli, K. pneumoniae) and antifungal activity against $A$. fumigatus, $C$. albicans, Geotrichum candidum at concentrations ranging between 8 and $31.25 \mu \mathrm{g} / \mathrm{mL}$.

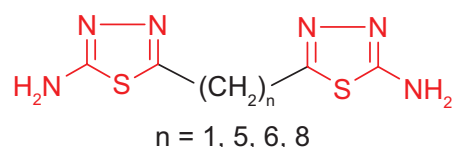

24

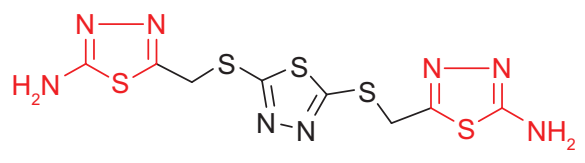

25

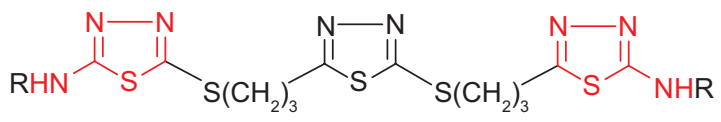

$\mathrm{R}=\mathrm{Ph}, \mathrm{Me}, \mathrm{Et}$

26

An attempt to prepare active compounds of the thiadiazole derivative series combining the xylosyl moiety and the aryltetrazole ring gave compound $\mathbf{2 7}$ exhibiting $S$. aureus inhibitory activity. ${ }^{79}$ It is well known that furan derivatives bearing a nitro group in the 5-position and a group of the general type $-\mathrm{C}=\mathrm{N}-\mathrm{N}=\mathrm{C}-$, which may be incorporated in a heterocycle, possess in vivo antibacterial properties. Sherman ${ }^{80}$ prepared 2-amino-5-(5' -nitro-2' -furyl)-1,3,4thiadiazole $\mathbf{2 8}$ with antibacterial activity in animals after oral or intramuscular administration. The free amine group

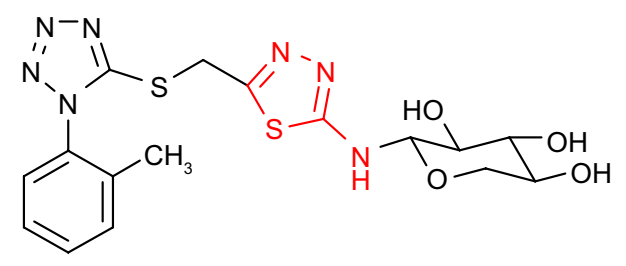

27<smiles>Nc1nnc(-c2ccc([N+](=O)[O-])o2)s1</smiles>

28

conferred the maximum antibacterial activity, while the substitution of amine group decreased the activity in the following order: methyl $>$ ethyl $>$ phenyl.

Demirbas et $\mathrm{l}^{81}$ have synthesized several 1-(5-arylamino$[1,3,4]$ thiadiazol-2-yl)methyl-4-amino-3-R-5-oxo4,5-dihydro-[1,2,4]triazoles 29 and $\mathbf{3 0}$ which exhibited antimicrobial properties on different microbial strains. $p$-Chlorophenyl derivative 29d and $p$-methoxyphenylamino derivative $\mathbf{3 0}$ showed the most potent antimicrobial activity against the tested microorganisms. For example, compound 30 showed promising antimicrobial activity against all the bacterial strains: E. coli, Yersinia pseudotuberculosis, P. aeruginosa, Enterococcus faecalis, $S$. aureus, B. cereus (diameter of the inhibition zone $\geq 20 \mathrm{~mm}$ ) with the best results against $E$. coli and $P$. aeruginosa (diameter of the inhibition zone $\geq 30 \mathrm{~mm}$ ). Methyl derivative 29a showed good activity against $E$. coli, $P$. aeruginosa, $K$. pneumoniae and B. subtilis strains (diameter of the inhibition zone $\geq 17 \mathrm{~mm}$ ). Benzyl derivative 29e showed good activity against $K$. pneumoniae (diameter of the inhibition zone $\geq 17 \mathrm{~mm}$ ) and moderate activity against $E$. coli, $S$. aureus and B. subtilis strains (diameter of the inhibition zone 11-16 mm), while phenyl derivative 29c exhibited moderate activity against $K$. pneumoniae (diameter of the inhibition zone 11-16 mm) and antifungal activity against Penicillium sp. (diameter of the inhibition zone $20 \mathrm{~mm}$ ). No antifungal activity was observed on the yeasts such as C. albicans, Candida tropicalis or Candida glabrata. The substitution of the - NH- group in arylamino unit by a hydrophobic methyl group decreased the antimicrobial activity. ${ }^{82,83}$

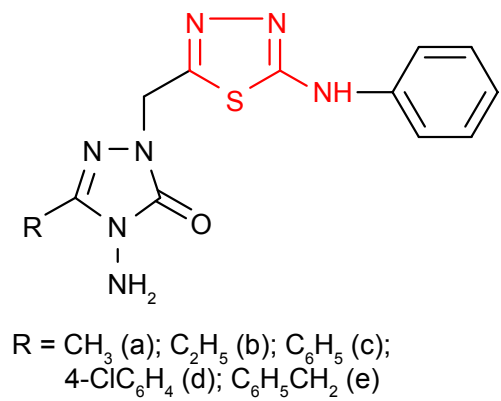

29 
<smiles>COc1ccc(Nc2nnc(Cn3nc(-c4ccc(C)cc4)n(N)c3=O)s2)cc1</smiles>

30

Following the discovery of the natural antimicrobial pyrazole C-glycoside, pyrazofurin, much attention has been given to the pyrazole derivatives. Compounds containing pyrazole moiety attached to the 1,3,4-thiadiazole ring have been synthesized by Bekhit et al. ${ }^{84}$ Among the studied compounds, the tolyl derivative $\mathbf{3 1}$ showed about half of the activity of ampicillin against Gram-positive microorganism S. aureus. Even if the antimicrobial activity is not very high, the complexity of the reported compounds makes them promising pharmacological agents. In the search for new antimicrobial agents, 2-amino-1,3,4-thiadiazole derivatives bearing isomeric pyridyl ring have been synthesized and the antibacterial studies have also been reported. The naphthyl derivative $\mathbf{3 2}$ exhibited very weak inhibitory activity against $S$. aureus and E. coli, while the benzyl derivative $\mathbf{3 3}$ was more

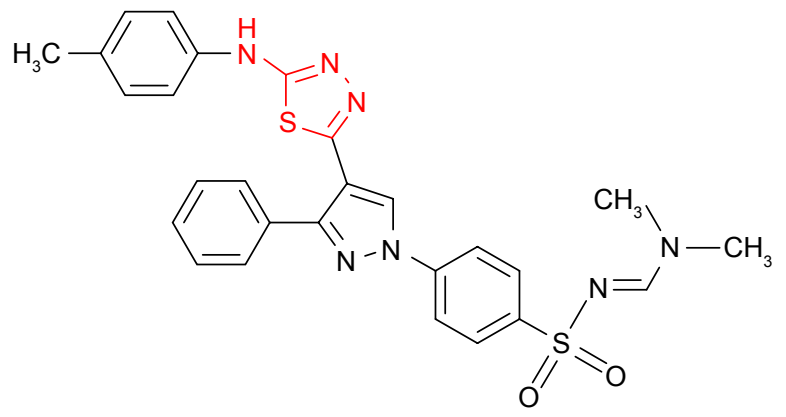

31

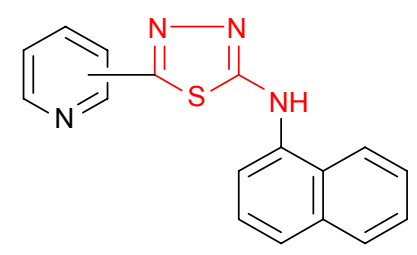

2-pyridyl, 3-pyridyl, 4-pyridyl

32

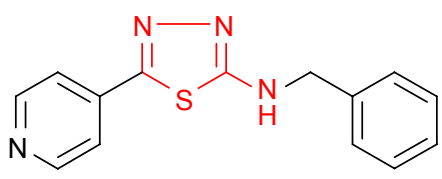

33 active than other studied compounds against tested Grampositive and Gram-negative bacterial strains. ${ }^{85,86}$

Similar hybrid compounds which have a 2-pyridyl ring linked to 1,3,4-thiadiazol moiety through a methylene group (eg, compound 34 ) also exhibited moderate activity against some Gram-positive cocci, Gram-negative rods and fungi. ${ }^{87}$ Some 1,3,4-thiadiazole derivatives such as $\mathbf{3 5}$ bearing pyrimidine ring have been tested for in vitro antimicrobial activity against $E$. coli and Rhizobium spp. Opposite to what was observed in the previous examples, the pyridyl derivatives 35e-f exhibited the best inhibition activity among the tested compounds. ${ }^{88}$<smiles>Clc1ccc(Nc2nnc(Cc3ccccn3)s2)cc1Cl</smiles>

34<smiles>[R]c1nc(Nc2nnc(S)s2)nc(-c2ccccc2O)c1[R]</smiles>

$\mathrm{R}=\mathrm{CH}_{3}, \mathrm{Cl}$;

$\mathrm{R}_{1}=$ 2-furyl (a,b); 2-thienyl (c,d); 2-pyridyl (e,f)

35

Andrews et al ${ }^{89}$ synthesized some new 2-amino-1,3,4-thiadiazole derivatives substituted at $\mathrm{C}-5$ of thiadiazole ring with dihydropyrimidine moiety. The compounds such as $\mathbf{3 6}$ were evaluated for in vitro antibacterial activity at a concentration of $10 \mu \mathrm{g} / \mathrm{mL}$ by measuring the inhibition area on agar plates (diffusion method). Moderate activity against $E$. coli was shown by nitro derivatives 36c-d using dimethyl sulfoxide (DMSO) as a control and ciprofloxacin as standard drug. Hydroxyl derivatives 36a-b exhibited moderate to good inhibitory activity against $P$. aeruginosa, $S$. aureus and $E$. coli.

New 2-[4-(4-bromophenyl)-5-(2-furyl)-4H-1,2,4-triazole3-yl]mercaptomethyl-5-alkyl/arylamino-1,3,4-thiadiazoles 37 were synthesized and have been evaluated for in vitro antifungal activity against Microsporum gypseum, Microsporum canis, T. mentagrophytes, Trichophyton rubrum and 
C. albicans. Both types of compounds bearing aliphatic and aromatic substituents inhibited the growth of fungal strains at concentrations ranging between 4 and $8 \mu \mathrm{g} / \mathrm{mL}$, the most susceptible microorganism being T. mentagrophytes (MIC value of $4 \mu \mathrm{g} / \mathrm{mL}) .{ }^{90}$

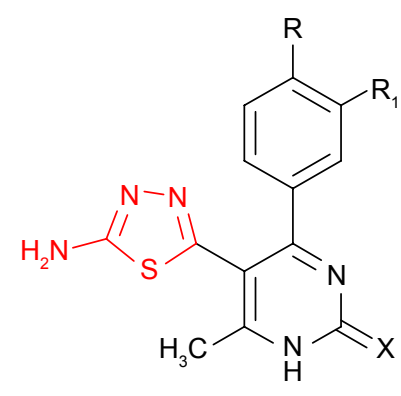

$$
\mathrm{X}=\mathrm{O}, \mathrm{S}
$$$$
\mathrm{R}=\mathrm{OH}, \mathrm{R}_{1}=\mathrm{H}(\mathrm{a}, \mathrm{b})
$$$$
\mathrm{R}=\mathrm{H}, \mathrm{R}_{1}=\mathrm{NO}_{2}(\mathrm{c}, \mathrm{d})
$$

36

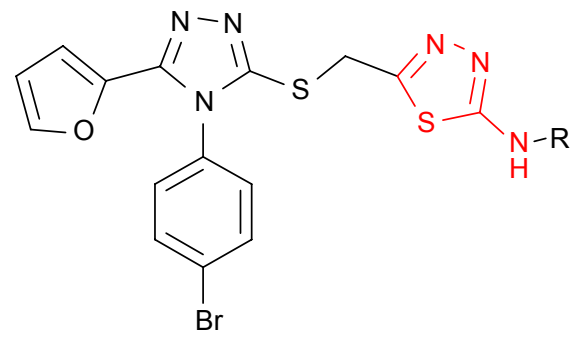

$$
\mathrm{R}=\mathrm{C}_{2} \mathrm{H}_{5} ; \mathrm{C}_{4} \mathrm{H}_{9} ; \mathrm{C}_{6} \mathrm{H}_{4} \mathrm{~F}(p) ; \mathrm{C}_{6} \mathrm{H}_{4} \mathrm{NO}_{2}(p)
$$

37

Onkol et $\mathrm{al}^{91}$ have synthesized several 2-[[1(2H)-phthalazinone-2-yl]methyl/ethyl]-5-arylamino-1,3,4-thiadiazole derivatives such as $\mathbf{3 8}$. The antimicrobial studies showed that the compounds are active against $B$. subtilis strains and two yeast-like fungi: C. albicans and Candida parapsilosis. Even if the antimicrobial activity was lower compared to the standard drugs, ampicillin and fluconazole, the tested compounds could be good starting materials for better antibacterial and antifungal agents. A number of 1-[1,3,4thiadiazol-2-yl]-3-methylthio-6,7-dihydrobenzo[c]thiophen4(5H)ones 39 have been evaluated for antimicrobial activity against several bacterial and fungal strains. The compounds exhibited antifungal activity against $C$. albicans and high potency against $B$. subtilis. The presence of a bulky group increased the antimicrobial activity. Thus, $p$-nitrophenyl derivative $39 \mathbf{d}$ had the same potency as nitrofurantoin against B. subtilis strains. ${ }^{92}$

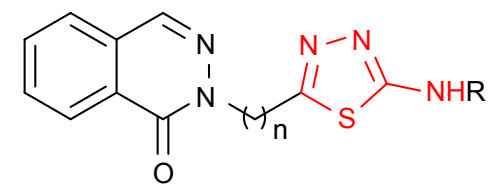

$\mathrm{n}=1,2$

$\mathrm{R}=$ phenyl; benzyl; phenethyl; $4-\mathrm{ClC}_{6} \mathrm{H}_{4} ; 4-\mathrm{CH}_{3} \mathrm{OC}_{6} \mathrm{H}_{4}$; $4-\mathrm{CH}_{3} \mathrm{C}_{6} \mathrm{H}_{4}$

38<smiles>[R]Nc1nnc(-c2sc([SiH3])c3c2CCCC3=O)s1</smiles>

$\mathrm{R}=\mathrm{CH}_{3}(\mathrm{a}) ; \mathrm{C}_{2} \mathrm{H}_{5}(\mathrm{~b}) ; n-\mathrm{C}_{4} \mathrm{H}_{9}(\mathrm{c}) ; 4-\mathrm{NO}_{2} \mathrm{C}_{6} \mathrm{H}_{4}(\mathrm{~d})$

39

Siddiqui and Alam ${ }^{93}$ and Siddiqui et $\mathrm{a}^{94}$ have synthesized some new 5-(1H-indol-3-ylmethyl)- $N$-(substituted phenyl)1,3,4-thiadiazol-2-amine derivatives such as 40. The antibacterial and antifungal studies showed good to high activity against E. coli and C. albicans, respectively, for some of the analyzed compounds.

Vasoya et $\mathrm{al}^{95}$ reported the synthesis and antimicrobial screening of new 2-(3'-chloro- $5^{\prime}$-phenoxybenzo $[b]$ thiophen2'-yl)-5-arylamino-1,3,4-thiadiazole derivatives such as $\mathbf{4 1}$. Upon the evaluation of antimicrobial activity, it has been found that almost all compounds exhibited antimicrobial activity against E. coli, Bacillus megaterium, S. aureus or $A$. niger at a concentration of $40 \mu \mathrm{g} / \mathrm{mL}$. The activity was comparable or higher than the reference drugs such as benzylpenicillin, amoxicillin, ciprofloxacin, erythromycin and griseofulvin. The findings revealed that antimicrobial activity was diminished by the introduction of the

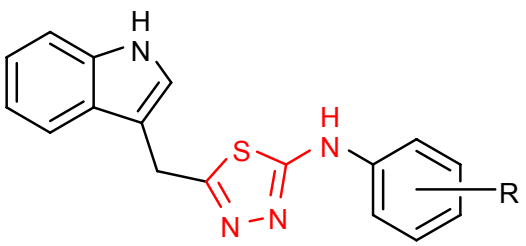

$\mathrm{R}=\mathrm{H} ; 2-\mathrm{Cl} ; 3-\mathrm{Cl} ; 4-\mathrm{Cl} ; 2-\mathrm{OCH}_{3}$

40 


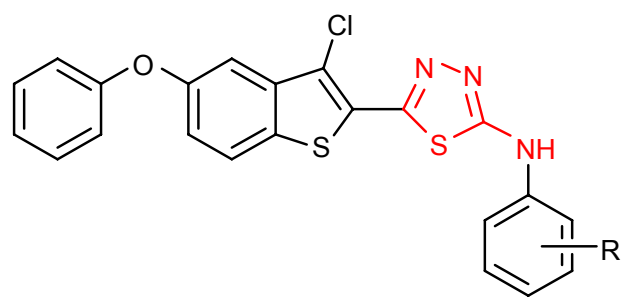

$\begin{aligned} \mathrm{R}= & \mathrm{H}(\mathrm{a}) ; 3-\mathrm{Cl}(\mathrm{b}) ; 4-\mathrm{Cl}(\mathrm{c}) ; 4-\mathrm{CH}_{3}(\mathrm{~d}) ; \\ & 4-\mathrm{CH}_{3} \mathrm{O}(\mathrm{e}) ; 2-\mathrm{NO}_{2}(\mathrm{f})\end{aligned}$

41

electron-donating groups (eg, methyl and methoxy) on C-2 of the arylamino group.

Other chlorobenzothiophene derivatives bearing the $\mathrm{N}$-imidazolylthiadiazolylamine moiety were investigated for their antimicrobial activity. The benzimidazole derivative $\mathbf{4 2}$ showed marked antifungal activity against $A$. niger, while the 4,5-dihydroimidazol derivative $\mathbf{4 3}$ showed moderate antibacterial activity against $B$. cereus. $^{96}$<smiles>[Al]c1nnc(Nc2nc3ccccc3[nH]2)s1</smiles>

42<smiles>[Al]c1nnc(NC2=NCCN2)s1</smiles><smiles></smiles>

43

2-(3',5'-Dichlorobenzo[b]thiophen-2'-yl)-5-arylamino1,3,4-thiadiazole derivatives 44 exhibited antimicrobial activity against bacterial and fungal strains. The SAR study showed that the arylamino substituent at C-5 of the thiadiazole ring can change the antimicrobial spectrum. Thus, the nitro derivative $44 c$ exhibited activity against $S$. aureus similar to benzylpenicillin, the $o$-tolylamino derivative 44a was as active as amoxicillin against Gram-negative bacteria E. coli and Proteus vulgaris, while the $p$-tolylamino derivative $44 \mathbf{b}$ exhibited antifungal activity against $A$. niger. ${ }^{97}$

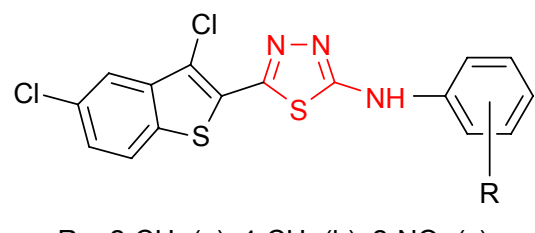

$\mathrm{R}=2-\mathrm{CH}_{3}(\mathrm{a}) ; 4-\mathrm{CH}_{3}(\mathrm{~b}) ; 2-\mathrm{NO}_{2}$ (c)

44
Amir et al ${ }^{39}$ have synthesized new 2-R-5-(6'-chloro-1',3'benzo[d]thiazol-2-yl-amino)-1,3,4-thiadiazoles $\mathbf{4 5}$, and the antimicrobial activity has been evaluated. The compounds having 2-acetoxyphenyl (45a), 2-naphtylmethyl (45b) and 2,4-dichlorophenyl (45c) groups at C-2 of thiadiazole ring showed potent antibacterial activity, while the compounds having 2-aminophenyl (45d) and 2,4-dichlorophenoxymethyl (45e) groups showed potent antifungal activity. New 1,3,4thiadiazole derivatives such as $\mathbf{4 6}$ incorporating a fluorobenzothiazole moiety have been synthesized by Vedavathi et al. The antimicrobial screening showed significant antibacterial and antifungal activity for some of the studied compounds (eg, morpholine and piperazine derivatives). ${ }^{55,98}$
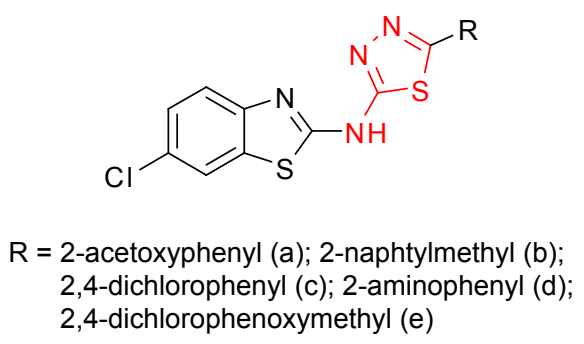

45

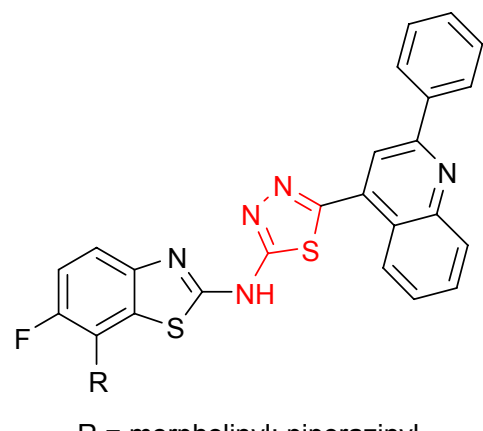

$\mathrm{R}=$ morpholinyl; piperazinyl

46

1,3,4-Thiadiazole derivatives $\mathbf{4 7 ,} \mathbf{4 8}$ and $\mathbf{4 9}$ bearing benzimidazole (47), benzoxazole (48) and benzothiazole (49) moiety, respectively, were screened for antibacterial activity against $E$. coli and Bacillus cirrhosis and antifungal activity against $A$. niger and Penicillium worthmanni. In comparison to norfloxacin and griseofulvin, all the tested compounds exhibited moderate to good antibacterial and antifungal activities at a concentration of $100 \mu \mathrm{g} / \mathrm{mL}$. It should be noted that pyridine-substituted compounds $47 \mathbf{b}, \mathbf{4 8 b}$ and 49b were more active at every concentration (100, 50 and $25 \mu \mathrm{g} / \mathrm{mL}$ ) than benzyl-substituted compounds. Among the three reported heterocyclic systems, the benzimidazole derivatives such as $\mathbf{4 7}$ have shown better antimicrobial activity. ${ }^{99}$ 


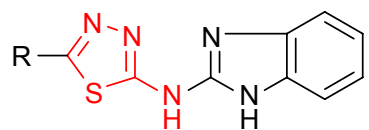

$\mathrm{R}=$ benzyl (a); 3-pyridyl (b)

47

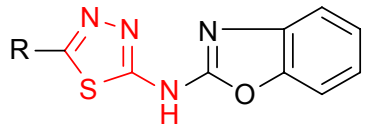

$\mathrm{R}=$ benzyl (a); 3-pyridyl (b)

48

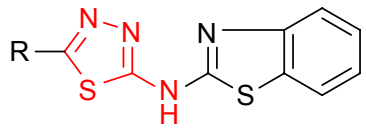

$\mathrm{R}=$ benzyl (a); 3-pyridyl (b)

49

The synthesis of new polymers derived from poly(vinyl chloride) (PVC) was carried out by Yousif et al. ${ }^{100}$ The modified PVC polymers 50 contain 1,3,4-thiadiazole ring and were obtained through the chlorine displacement reaction from PVC with heterocyclic moiety. The preliminary screening for the antimicrobial activity of the polymers was performed on three bacterial strains: S. aureus, Streptococcus viridans and E. coli and three fungal strains: Fusarium oxysporum, Alternaria alternata and Alternaria solani with promising results.

8-Hydroxyquinoline derivatives, such as nitroxoline and chlorquinaldol, are well-known antimicrobial agents used for the treatment of urinary and intestinal infection, respectively. A new series of metal chelates of 5-[4-chlorophenyl(1,3,4-thiadiazol)-2-ylaminomethylene]-8-hydroxyquinoline derivative 51 was synthesized by Patel and Singh. ${ }^{101}$ The antifungal activity of the ligand and its transition metal chelates were evaluated. The findings suggested that the chelates are more toxic compared to the ligand. $\mathrm{Cu}^{2+}$ chelate 51a was the most active among the studied compounds.

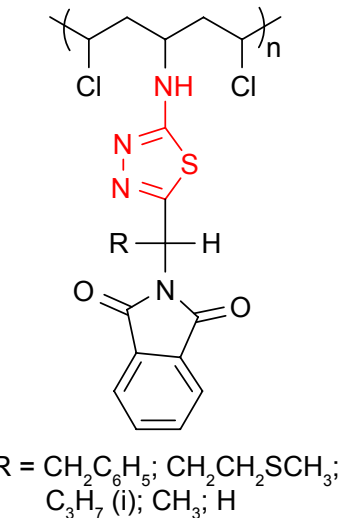

50

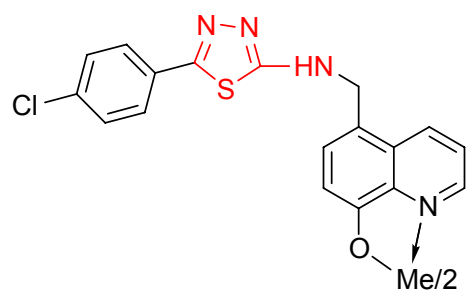

$\mathrm{Me}=\mathrm{Cu}^{2+}(\mathrm{a}) ; \mathrm{Ni}^{2+}(\mathrm{b}) ; \mathrm{Co}^{2+}(\mathrm{c})$ $\mathrm{Zn}^{2+}(\mathrm{d}) ; \mathrm{Mn}^{2+}(\mathrm{e})$

51
The in vitro activity of 1,3,4-thiadiazole derivatives $\mathbf{5 2}$ bearing an imidazo[2,1- $b]$ thiazole moiety has been evaluated against bacterial strains of $S$. aureus, $P$. aeruginosa and E. coli and fungal strains of C. albicans, C. parapsilosis, Candida krusei, T. mentagrophytes, Trichophyton tonsurans and $M$. gypseum. The ethyl derivative $\mathbf{5 2} \mathbf{b}$ showed the highest activity against $E$. coli, and both methyl (52a) and ethyl (52b) derivatives were very active against $T$. tonsurans. ${ }^{102}$

Hybrid molecules $\mathbf{5 3}$ incorporating a fluoroquinolone moiety and the thiadiazole ring have been synthesized, and the antimicrobial activity was investigated. The screening data revealed that the tested compounds showed moderate to excellent antibacterial and antifungal activity. Thus, the phenyl derivative 53a was more active against $A$. niger than nystatin, and the tolyl derivative $\mathbf{5 3} \mathbf{b}$ was more active against $P$. aeruginosa than chloramphenicol. Compared to the known antibacterial fluoroquinolones, the hybrid compounds 53a-b showed a very narrow antimicrobial spectrum. ${ }^{103}$

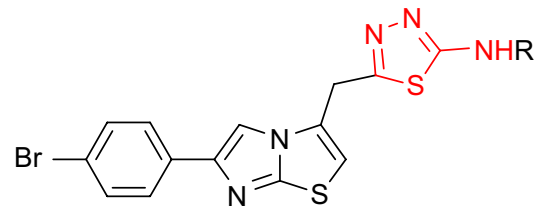

$$
\mathrm{R}=\mathrm{CH}_{3}(\mathrm{a}) ; \mathrm{C}_{2} \mathrm{H}_{5}(\mathrm{~b})
$$

52

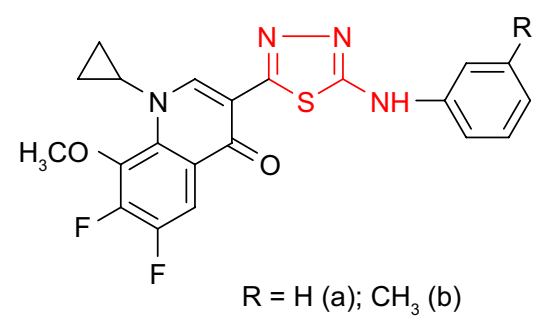

53

The hybrid derivatives 54 having the 1,3,4-thiadiazole ring attached to the antipyrine moiety showed weak inhibitory activity against Gram-positive bacteria $S$. aureus and B. subtilis and no activity against some Gram-negative bacteria. ${ }^{104}$ However, the introduction of a third heterocyclic nucleus in the structure of some hybrid antipyrine derivatives gave the compounds such as $\mathbf{5 5}$ with very good antimicrobial activity against enteric bacteria such as E. coli, Enterobacter aerogenes and $Y$. pseudotuberculosis and Gram-negative bacteria $P$. aeruginosa (inhibition zone $>20 \mathrm{~mm}$ at $5 \mu \mathrm{g} / \mathrm{mL}$ ). The most active derivative 55a was two times more active than ampicillin. ${ }^{105}$ 


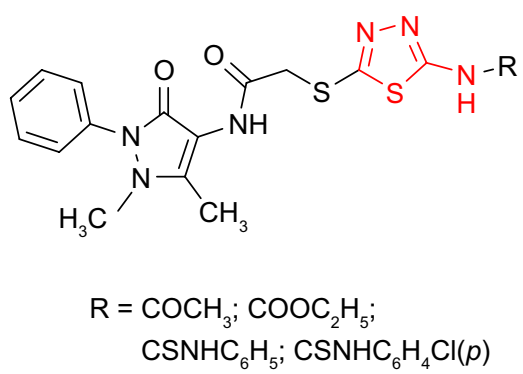

54

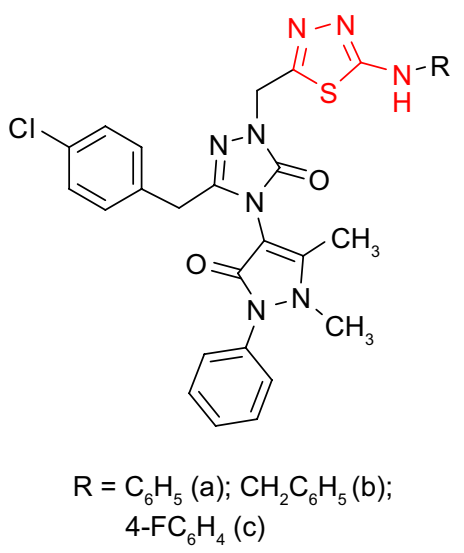

55

Hybrid sulfonamide-1,3,4-thiadiazole derivatives such as $\mathbf{5 6}$, combining two pharmacologically active molecules in one new compound, have been synthesized by Camoutsis et al. ${ }^{106}$ The antimicrobial study against Gram-positive bacteria, Gram-negative bacteria and fungi has revealed some differences depending on the nature of the substituents. The relationships between the structure and the antimicrobial activity showed that pyrrolidine, piperidine and methylpiperazine derivatives are more active, the pyrrolidine derivative 56a exhibits the best antibacterial activity and the methylpiperazine derivative 56c exhibits the best antifungal activity. Moreover, the SAR study showed that the inhibitory effect depends on the substitution at the phenylamino group. Thus, substitution at the para position of the benzene ring with the $\mathrm{CF}_{3}$ group or chlorine improved the antimicrobial activity which indicates that the antimicrobial activity is correlated with the lipophilicity of the compounds expressed by the calculated values of $\mathrm{C} \log \mathrm{P}$.

Hybrid coumarin-1,3,4-thiadiazole derivatives such as 57 have been synthesized by Serban et al, ${ }^{107-109}$ and the antimicrobial activity has been investigated. The preliminary results of antimicrobial activities indicated that some compounds exhibited moderate to good antibacterial and antifungal activity with a narrow antimicrobial spectrum limited to P. vulgaris, P. aeruginosa and C. albicans. Except the 3-[5-(4- methylphenylamino)-1,3,4-thiadiazol-2-yl]-6-nitrocoumarin derivative $\mathbf{5 7} \mathbf{h}$, which had no activity against the bacterial and fungal strains, all the tested compounds showed good activity against $P$. aeruginosa at a concentration of $50 \mu \mathrm{g} /$ disk (inhibition zone of 19-22 mm), which indicates that the coumarin1,3,4-thiadiazole system might be a promising scaffold for new antibacterial agents. In addition, the introduction of a nitro group on the coumarin ring improved the antibacterial activity against $P$. vulgaris (compounds $57 \mathbf{g}$ and $\mathbf{5 7} \mathbf{k}$, inhibition zone $>16 \mathrm{~mm}$ ), while the coumarin derivatives without the nitro group showed moderate antifungal activity against C. albicans (compounds 57b, 57e and 57f, inhibition zone $>12 \mathrm{~mm}$ ). All the tested compounds were inactive against $S$. aureus, E. coli and K. pneumoniae.

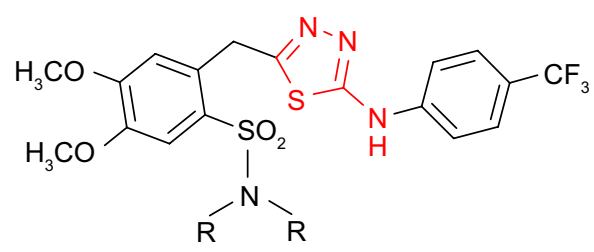<smiles>[R]N1CCCC1</smiles><smiles>[AlH2]N1CCCCC1</smiles>
(b); $-\mathrm{N} \mathrm{N}-\mathrm{CH}_{3}(\mathrm{c})$ 56

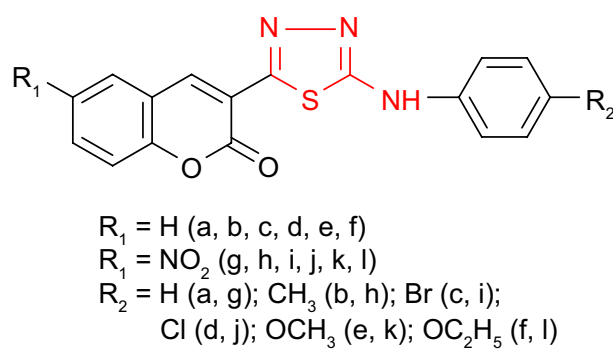

57

\section{Antitubercular activity}

The treatment of infections caused by Mycobacterium tuberculosis strains has rapidly become a health problem due to the increasing resistance of bacteria to common antitubercular drugs. Moreover, the multidrug-resistant tuberculosis (MDR-TB) coupled with the increasing overlap of the AIDS and tuberculosis pandemics have brought tuberculosis among the major worldwide health problems. The development of new classes of antitubercular drugs containing a core of 2-amino-1,3,4-thiadiazole moiety is a very challenging task to many scientists.

Antibacterial quinolones became interesting medicines because of the broad antibacterial spectrum on both 
Gram-positive and Gram-negative bacteria. Fluoroquinolone derivatives have been introduced in therapy since 1980s and have multiple recommendations, some of them (eg, gatifloxacin, sparfloxacin and moxifloxacin) being also used in tuberculosis treatment in the cases involving resistance or intolerance to first-line antituberculosis therapy. ${ }^{110,111}$

A new class of antibacterial fluoroquinolones is represented by sulfonyl-fluoroquinolones which are hybrid molecules incorporating a sulfonamide moiety and a fluoroquinolone ring. Sulfonyl-fluoroquinolones are particularly active against Gram-positive bacteria. Thus, Talath and Gadad ${ }^{112}$ have synthesized several 7-[4-(5-amino1,3,4-thiadiazol-2-sulfonyl)piperazin-1-yl]fluoroquinolone derivatives such as 58. The unsubstituted cyclopropyl 58a and ethyl $\mathbf{5 8 b}$ derivatives showed moderate activity against M. tuberculosis strain $\mathrm{H}_{37} \mathrm{Rv}$ at $\mathrm{MIC}$ of $10 \mu \mathrm{g} / \mathrm{mL}$ with respect to reference drug, isoniazid. The studied compounds showed antibacterial activity against other Gram-positive bacteria (S. aureus, E. faecalis, Bacillus sp., MIC $=1-5 \mu \mathrm{g} / \mathrm{mL}$ ) better than the reference fluoroquinolones (ciprofloxacin, norfloxacin, sparfloxacin and gatifloxacin) and almost similar activity as reference drugs against Corynebacterium sp. The best activity was exhibited by the derivatives 58c and $\mathbf{5 8 d}$, which were active against all the tested Gram-positive bacteria ( $\mathrm{MIC}=1-5 \mu \mathrm{g} / \mathrm{mL}$ ). All derivatives exhibited poor activity against Gram-negative bacteria. These results are in agreement with some earlier reports which showed that substitution with aryl/heteroaryl groups at C-7 of fluoroquinolone ring is responsible for distinguishing between antibacterial activity against Gram-positive and Gram-negative bacteria. ${ }^{112-114}$ The reason might be differences in the structure of the cell wall of Gram-positive bacteria and Gram-negative bacteria. The cell walls of the Gram-positive bacteria contain peptidoglycan and bacterium may or may not be surrounded by a polysaccharide envelope. The cell walls of the Gramnegative bacteria contain lipopolysaccharides. The attack site of anti-cell wall agents is the peptidoglycan layer which is essential for the survival of bacteria. The damage of this layer leads to changes in the bacterial cell wall resulting in death. ${ }^{115}$ In the case of compounds such as quinolones, which act as antibacterial agents by different mechanism, the structure of the cell wall is still important. The peptidoglycan layer of the Gram-positive bacteria allows the hydrophobic compounds to cross the cell wall and penetrate into the cell, while the lipopolysaccharides of the Gram-negative bacteria repel the hydrophobic compounds. The impermeable cell wall<smiles>[R]c1c(F)c(N2CC([R])N(S(=O)(=O)c3nnc(N)s3)C([R])C2)c([R])c2c1c(=O)c(C(=O)O)cn2[R]</smiles>

\begin{tabular}{llllll} 
& $\mathbf{R}$ & $\mathbf{R}_{\mathbf{1}}$ & $\mathbf{R}_{\mathbf{2}}$ & $\mathbf{R}_{\mathbf{3}}$ & $\mathbf{R}_{\mathbf{4}}$ \\
\hline $\mathrm{a}$ & \multicolumn{1}{c}{$\mathrm{H}$} & $\mathrm{H}$ & $\mathrm{H}$ & $\mathrm{H}$ \\
$\mathrm{b}$ & $\mathrm{C}_{2} \mathrm{H}_{5}$ & $\mathrm{H}$ & $\mathrm{H}$ & $\mathrm{H}$ & $\mathrm{H}$ \\
$\mathrm{c}$ & $\mathrm{NH}_{2}$ & $\mathrm{~F}$ & $\mathrm{CH}_{3}$ & $\mathrm{CH}_{3}$ \\
$\mathrm{~d}$ & $\mathrm{H}$ & $\mathrm{OCH}_{3}$ & $\mathrm{H}$ & $\mathrm{CH}_{3}$ \\
\hline
\end{tabular}

makes the Gram-negative bacteria more resistant to large or intensively hydrophobic molecules. ${ }^{6}$

New $\alpha$-[5-(5-amino-1,3,4-thiadiazol-2-yl)-imidazol2-ylthio] acetic acid derivatives such as $\mathbf{5 9}$ were in vitro evaluated for antitubercular activity against M. tuberculosis strain $\mathrm{H}_{37} \mathrm{Rv}$. Compared to standard drug, rifampicin, the tested compounds exhibited low activity ( $\mathrm{MIC} \geq 6.25 \mu \mathrm{g} / \mathrm{mL}$, inhibition $\leq 24 \%$ ), but they might be considered as good starting compounds for better antitubercular agents. ${ }^{116}$ In comparison, the dichlorobenzothiophene thiadiazole 44c exhibited very high activity against $M$. tuberculosis strain $\mathrm{H}_{37} \mathrm{Rv}$ in BACTEC 12B medium (98\% inhibition) at the concentration of $6.25 \mu \mathrm{g} / \mathrm{mL} .{ }^{97}$<smiles></smiles>

59

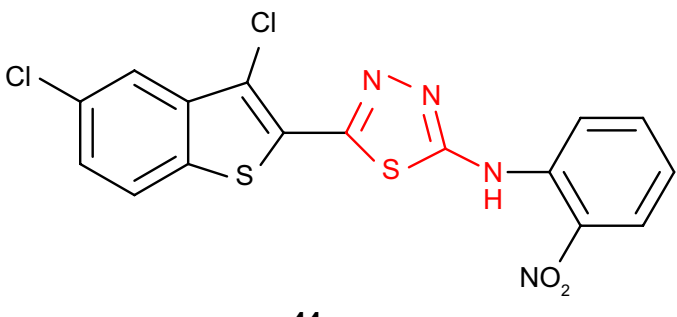

$44 c$ 
Karakus and Rollas ${ }^{117}$ have synthesized new $N$-phenyl$N^{\prime}$-[4-(5-alkyl/arylamino-1,3,4-thiadiazol-2-yl)phenyl]thioureas 60. Using BACTEC 460 radiometric system (Becton Dickinson, Cockeysville, MD, USA), the in vitro activity against M. tuberculosis strain $\mathrm{H}_{37} \mathrm{Rv}$ at $6.25 \mu \mathrm{g} / \mathrm{mL}$ has been studied. Compared to standard drug, rifampicin, the best inhibitory activity (67\%) was shown by the derivative 60a having a cyclohexyl group, while the derivative 60b having a $p$-chlorophenyl group showed $32 \%$ inhibition against M. tuberculosis. Other derivatives exhibited different degrees of inhibition (16\% for compound 60c, $6 \%$ for compound 60d).

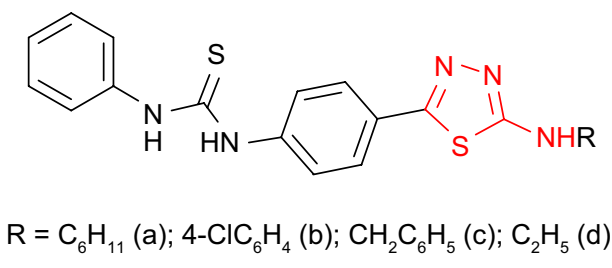

60

Similarly, 2-amino-5-R-1,3,4-thiadiazole derivatives such as $\mathbf{6 1}$ were investigated for antitubercular activity. Among the tested compounds, 2-phenylamino-5(4-fluorophenyl)-1,3,4-thiadiazole 61e showed the best inhibitory activity (69\%), while 2-phenylamino-5-phenyl-1,3,4-thiadiazole 61a showed 65\% inhibitory activity against in vitro growing $M$. tuberculosis $\mathrm{H}_{37} \mathrm{Rv}$ at a concentration of $6.25 \mu \mathrm{g} / \mathrm{mL}$. Other studied molecules were classified as high activity compounds (28 derivatives, inhibition activity $\geq 35 \%$ ), and this structure may

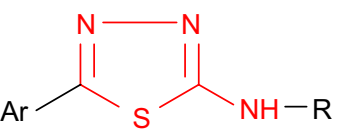

61

\begin{tabular}{llll}
\hline & $\mathbf{A r}$ & $\mathbf{R}$ & Inhib (\%) \\
\hline $\mathrm{a}$ & $\mathrm{C}_{6} \mathrm{H}_{5}$ & $\mathrm{C}_{6} \mathrm{H}_{5}$ & 65 \\
b & $\mathrm{C}_{6} \mathrm{H}_{5}$ & $4-\mathrm{FC}_{6} \mathrm{H}_{4}$ & 50 \\
c & $4-\mathrm{ClC}_{6} \mathrm{H}_{4}$ & $\mathrm{C}_{6} \mathrm{H}_{5}$ & 50 \\
d & $4-\mathrm{ClC}_{6} \mathrm{H}_{4}$ & $4-\mathrm{FC}_{6} \mathrm{H}_{4}$ & 54 \\
e & $4-\mathrm{FC}_{6} \mathrm{H}_{4}$ & $\mathrm{C}_{6} \mathrm{H}_{5}$ & 69 \\
f & $4-\mathrm{FC}_{6} \mathrm{H}_{4}$ & $4-\mathrm{FC}_{6} \mathrm{H}_{4}$ & 52 \\
g & $4-\mathrm{C}_{5} \mathrm{H}_{4} \mathrm{~N}$ & $4-\mathrm{BrC}_{6} \mathrm{H}_{4}$ & 53 \\
h & $4-\mathrm{C}_{5} \mathrm{H}_{4} \mathrm{~N}$ & $4-\mathrm{ClC}_{6} \mathrm{H}_{4}$ & 59 \\
\hline
\end{tabular}

be considered a good scaffold for the development of new antituberculosis agents. The electronic topological method (ETM) and feed-forward neural networks (FFNNs), which were used for the structure-antituberculosis activity relationship study, gave a system of pharmacophores and anti-pharmacophores able to separate the examined compounds in active and inactive compounds. According to these methods, low-activity molecules form a buffer zone consisting of compounds that can include both pharmacophores and anti-pharmacophores. ${ }^{42}$

The antimycobacterial activity against $M$. tuberculosis of 1,3,4-thiadiazole derivatives bearing an imidazo[2,1- $b$ ] thiazole moiety has been evaluated, the most active compound being the phenylamino derivative $\mathbf{6 2}$ (16\% inhibition, MIC $>6.25 \mu \mathrm{g} / \mathrm{mL}) .{ }^{102}$ Vasoya et al ${ }^{95}$ have reported the antitubercular activity against $M$. tuberculosis of some 2-(3'chloro-5'-phenoxybenzo[ $b]$ thiophen-2'-yl)-5-arylamino1,3,4-thiadiazole derivatives such as $\mathbf{4 1}$. In comparison to the antimicrobial screening of the same compounds, the derivatives bearing the electron-donating groups (eg, methyl and methoxy) at C-2 and C-4 of the arylamino group showed higher activity, the most active compound being 2-(3'-chloro5 -phenoxybenzo[ $b]$ thiophen-2'-yl)-5-( $p$-methoxyphenyl) amino-1,3,4-thiadiazole 41e (91\% inhibition at the concentration of $6.25 \mu \mathrm{g} / \mathrm{mL}$ ).

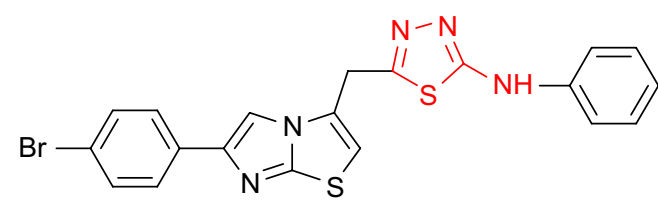

62

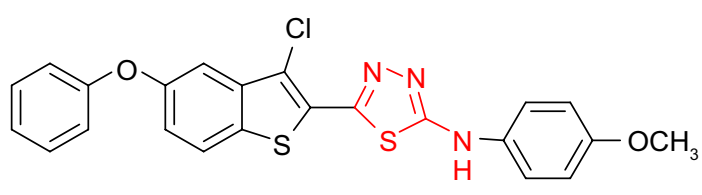

$41 e$

New $N$-[5-(1-amino-2-phenylethyl)-1,3,4-thiadiazol-2-yl]6-fluoro-7-substituted 1,3-benzothiazol-2-amine derivatives such as 63 have been in vitro evaluated for antitubercular activity against $M$. tuberculosis strain $\mathrm{H}_{37} \mathrm{Rv}$. The compounds showed promising antitubercular activity in comparison to standard drugs, rifampicin and isoniazid. ${ }^{118}$ Bayrak et al ${ }^{105}$ hybridized antipyrine with 1,3,4-thiadiazole and 1,2,4-triazole rings, 
getting the compounds such as $\mathbf{5 5}$. Even if the synthesized compounds were completely inactive against Gram-positive microorganisms such as $S$. aureus, E. faecalis or B. cereus, the studied compounds exhibited good inhibitory activity (inhibition zone of $25 \mathrm{~mm}$ at $5 \mu \mathrm{g} / \mathrm{mL}$ ) against Mycobacterium smegmatis which is an atypical factor of tuberculosis.

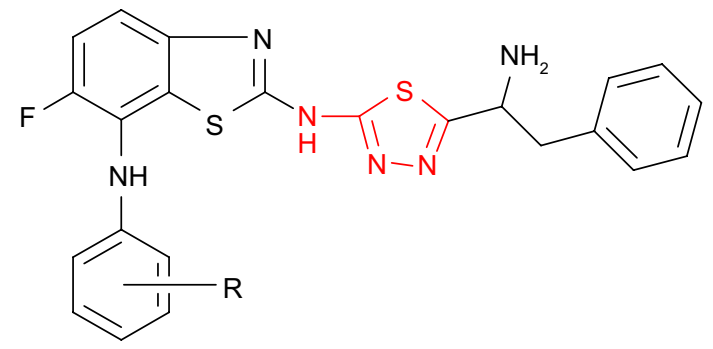

$\mathrm{R}=o, m, p-\mathrm{NO}_{2} ; o, m, p-\mathrm{CH}_{3} \mathrm{O} ; o-\mathrm{Cl}$

63

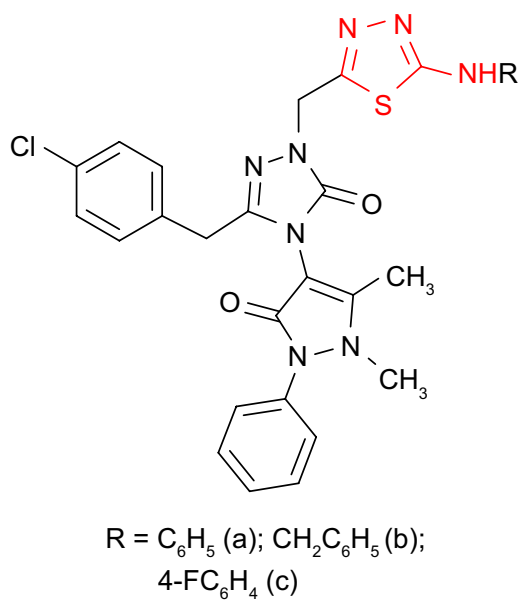

55

Other hybrid molecules incorporating the 1,3,4-thiadiazole ring and benzimidazole (47), benzoxazole (48) and benzothiazole (49) moiety were screened for in vitro antitubercular activity against $M$. tuberculosis $\mathrm{H}_{37} \mathrm{Rv}$ strain using the microplate Alamar blue assay (MABA). Compounds demonstrating at least $90 \%$ inhibition in preliminary screening were further evaluated to determine the MIC. All the compounds exhibited inhibitory activity against M. tuberculosis with a rate of inhibition between $53 \%$ and $95 \%$ at a concentration of $6.25 \mu \mathrm{g} / \mathrm{mL}$. Out of all heterocyclic derivatives, the benzoxazole derivatives such as $\mathbf{4 8}$ have shown the best inhibitory activity (93\% for $\mathbf{4 8 a}$ and $95 \%$ for $48 \mathrm{~b}$ ), while the benzimidazole derivatives such as 47 have shown the moderate inhibitory activity $(77 \%$ for $\mathbf{4 7 a}$ and $74 \%$ for $\mathbf{4 7 b}) .{ }^{99}$

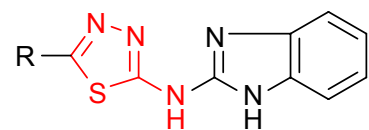

$\mathrm{R}=$ benzyl (a); 3-pyridyl (b)

47

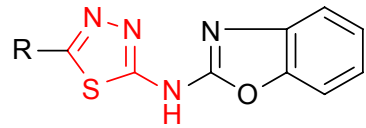

$\mathrm{R}=$ benzyl (a); 3-pyridyl (b)

48

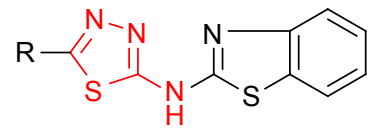

$\mathrm{R}=$ benzyl (a); 3-pyridyl (b)

49

Some thiadiazole derivatives designed as $M$. tuberculosis inhibitors were tested using BACTEC 460 radiometric system. The antitubercular activity of 2-(alkyl/arylamino)5-(4-aminophenyl)-1,3,4-thiadiazoles 64 was compared to those of the Schiff bases $\mathbf{6 5}$ obtained by the condensation of the starting thiadiazoles with aromatic and heterocyclic aldehydes. Some Schiff bases synthesized from salicylaldehyde and 3-nitrobenzaldehyde and bearing an arylamino group at $\mathrm{C}-2$ of thiadiazole ring were more active than the starting thiadiazoles (eg, compounds 65c-f). All the Schiff bases having an alkylamino group at $\mathrm{C}-2$ of thiadiazole ring were less active than the starting thiadiazoles (compounds 65a-b). 2-Phenylamino-5-[4-(2-hydroxybenzylideneamino) phenyl]-1,3,4-thiadiazole 65c showed the highest inhibition $(51 \%$, MIC $>6.25 \mu \mathrm{g} / \mathrm{mL}),{ }^{119}$ which is in agreement with other studies indicating that the conjugation of hydroxyl ligand with the imine group synergistically enhances the antimycobacterial activity. ${ }^{120}$

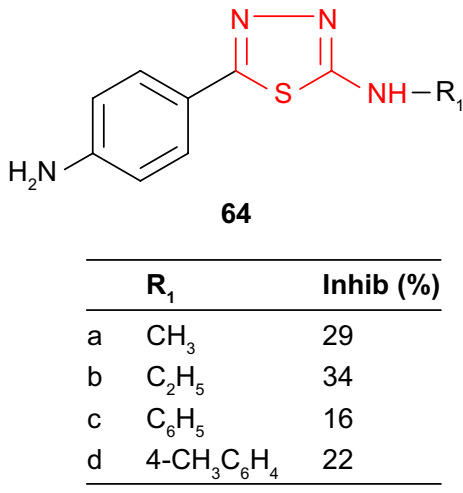


<smiles>[R]C=Nc1ccc(-c2nnc(N[R])s2)cc1</smiles>

\begin{tabular}{llll}
\hline & $\mathbf{R}_{2}$ & $\mathbf{R}_{1}$ & Inhib (\%) \\
\hline a & $2-\mathrm{HOC}_{6} \mathrm{H}_{4}$ & $\mathrm{C}_{2} \mathrm{H}_{5}$ & 0 \\
b & $3-\mathrm{NO}_{2} \mathrm{C}_{6} \mathrm{H}_{4}$ & $\mathrm{C}_{2} \mathrm{H}_{5}$ & 0 \\
c & $2-\mathrm{HOC}_{6} \mathrm{H}_{4}$ & $\mathrm{C}_{6} \mathrm{H}_{5}$ & 51 \\
d & $3-\mathrm{NO}_{2} \mathrm{C}_{6} \mathrm{H}_{4}$ & $\mathrm{C}_{6} \mathrm{H}_{5}$ & 29 \\
e & $2-\mathrm{HOC}_{6} \mathrm{H}_{4}$ & $4-\mathrm{CH}_{3} \mathrm{C}_{6} \mathrm{H}_{4}$ & 36 \\
f & $3-\mathrm{NO}_{2} \mathrm{C}_{6} \mathrm{H}_{4}$ & $4-\mathrm{CH}_{3} \mathrm{C}_{6} \mathrm{H}_{4}$ & 34 \\
\hline
\end{tabular}

Starting from L-methionine, Tatar et a ${ }^{121}$ synthesized different phenylamino-1,3,4-thiadiazole derivatives. 1,3,4Thiadiazole benzamide 66 and 1,3,4-thiadiazole thiourea 67 exhibited antimycobacterial activity against $M$. tuberculosis $\mathrm{H}_{37} \mathrm{Rv}$ strain with MIC values of 79.50 and $61.77 \mu \mathrm{M}$, respectively. Unfortunately, the compounds proved low selectivity with minimum cytotoxic concentration (MCC) values lower than MIC values.<smiles>CCCC(NC(=O)c1ccccc1)c1nnc(Nc2ccccc2)s1</smiles>

66<smiles>CCCC(NC(=S)Nc1ccc(Cl)c(C(F)(F)F)c1)c1nnc(Nc2ccccc2)s1</smiles>

67

\section{Fungicidal and herbicidal activities}

The fungicidal activity of thiadiazole derivatives against A. niger and Harpophora oryzae and their potential application as pesticides in agriculture has been previously reported. ${ }^{122,123}$ Some sulfide, sulfoxide and sulfonamide thiadiazoles were also reported for their fungicidal activity against Gibberella zeae, Botrytis cinerea, Sclerotinia sclerotiorum, F. oxysporum or Cytospora mandshurica. ${ }^{6}$ In this connection, various derivatives containing 2-amino-1,3,4-thiadiazole system have been prepared. 2-Arylamino-5-glycosyl-1, 3,4-thiadiazole derivatives such as $\mathbf{6 8}$ were synthesized by Zong et al, ${ }^{124}$ and the fungicidal activity against six fungal species: S. sclerotiorum, Phytophthora parasitica, B. cinerea, Rhizoctonia solani, Pyricularia oryzae and Phoma asparagi was in vitro investigated. Most of the 20 studied compounds displayed good fungicidal activities against $S$. sclerotiorum (12 compounds with inhibition rate of $\geq 85 \%$ ) and $P$. oryzae (seven compounds with inhibition rate of $\geq 80 \%$ ) at a concentration of $50 \mu \mathrm{g} / \mathrm{mL}$. Further studies against S. sclerotiorum at the concentrations of $50,20,10,5$ and $2 \mu \mathrm{g} / \mathrm{mL}$ were used to determine the effective concentration values $\mathrm{EC}_{50}$. About half of the studied compounds displayed good fungicidal activity with $\mathrm{EC}_{50}<3 \mu \mathrm{g} / \mathrm{mL}$. The SAR studies showed that the compounds with two electron-withdrawing groups at the benzene ring exhibited the best fungicidal activity. Thus, compounds 68b $\left(\mathrm{EC}_{50}=0.29 \mu \mathrm{g} / \mathrm{mL}\right)$ and $\mathbf{6 8 j}\left(\mathrm{EC}_{50}=0.46 \mu \mathrm{g} / \mathrm{mL}\right)$ are comparable with the commercial fungicide, chlorothalonil. In comparison, the compounds with two electron-donating groups at the benzene ring, such as 68a and $\mathbf{6 8 f}$, displayed only moderate fungicidal activity. Furthermore, SAR studies revealed the importance of the hydroxyl protecting group in the sugar ring. Thus, the compounds without any hydroxyl group protection in the sugar ring displayed moderate to significant decrease in their fungicidal activity. In addition, the allyl protecting group was more efficient for the fungicidal activity compared to the acetyl protecting group. In general, the allyl derivatives displayed better fungicidal activity against the six fungal species than the acetyl derivatives (eg, 68c and 68h, 68d and $68 \mathrm{i}$ and $68 \mathrm{e}$ and $68 \mathrm{j}$ ). ${ }^{124}$

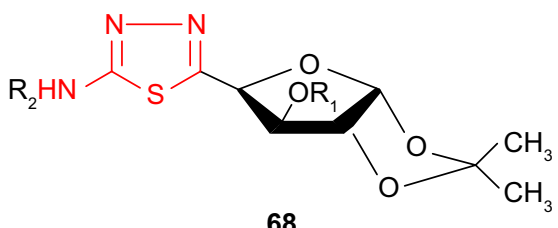

68

\begin{tabular}{|c|c|c|c|}
\hline & $R_{1}$ & $\mathbf{R}_{2}$ & $\mathrm{EC}_{50}$ \\
\hline a & $\mathrm{COCH}_{3}$ & $2,4-\left(\mathrm{CH}_{3}\right)_{2} \mathrm{C}_{6} \mathrm{H}_{3}$ & 7.11 \\
\hline$b$ & $\mathrm{COCH}_{3}$ & $3,4-\mathrm{Cl}_{2} \mathrm{C}_{6} \mathrm{H}_{3}$ & 0.29 \\
\hline C & $\mathrm{COCH}_{3}$ & $2,5-\mathrm{Cl}_{2} \mathrm{C}_{6} \mathrm{H}_{3}$ & 3.94 \\
\hline d & $\mathrm{COCH}_{3}$ & 1-Naphthyl & 22.53 \\
\hline e & $\mathrm{COCH}_{3}$ & $4-\mathrm{Cl}-3-\mathrm{CF}_{3} \mathrm{C}_{6} \mathrm{H}_{3}$ & 1.50 \\
\hline$f$ & allyl & $2,4-\left(\mathrm{CH}_{3}\right)_{2} \mathrm{C}_{6} \mathrm{H}_{3}$ & 9.92 \\
\hline g & allyl & $3,4-\mathrm{Cl}_{2} \mathrm{C}_{6} \mathrm{H}_{3}$ & 1.50 \\
\hline $\mathrm{h}$ & allyl & $2,5-\mathrm{Cl}_{2} \mathrm{C}_{6} \mathrm{H}_{3}$ & 1.62 \\
\hline $\mathrm{i}$ & allyl & 1-Naphthyl & 2.00 \\
\hline j & allyl & $4-\mathrm{Cl}-3-\mathrm{CF}_{3} \mathrm{C}_{6} \mathrm{H}_{3}$ & 0.46 \\
\hline
\end{tabular}


Yadav et al ${ }^{125}$ have synthesized 2-amino-5-substituted1,3,4-thiadiazoles $\mathbf{6 9}$, and the in vitro fungicidal activity against $P$. oryzae and $R$. solani at $500 \mathrm{ppm}$ was investigated. Fungicidal screening data indicated a moderate activity compared to the reference fungicide, carbendazim, the tested compounds being more active against $P$. oryzae than $R$. solani. The nature and the position of the substituents of the phenyl ring significantly changed the biological activity. Among the tested compounds, the chlorosubstituted derivatives 69a, 69b and 69d have shown greater activity ( $P$. oryzae inhibition rate between $32 \%$ and $42 \%$ ) than the methylated ones (eg, $69 c$, . oryzae inhibition rate of $16 \%$ ), the para chlorinated compound 69a being the most active. Methylation of the $p$-chloroderivative decreased the activity on both fungi.

Chu et al ${ }^{126}$ have synthesized several $\omega$-(5-arylamino1,3,4-thiadiazol-2-thio)- $\omega$-(1H-1,2,4-triazol-1-yl)acetophenone derivatives such as $\mathbf{7 0}$ which exhibited, at a concentration of $50 \mathrm{ppm}$, fungicidal activity against some pathogenic fungi of plants such as leaf rust of barley, leaf spot of beet, early blight of tomato, gray mold of cucumber and sclerotium blight of colza with an inhibition rate between $5 \%$ and $66.6 \%$. Chemical modification of these structures might give good fungicidal agents for agriculture.

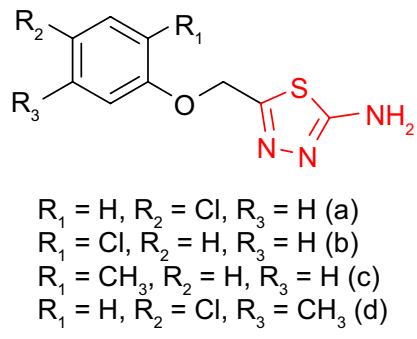

69

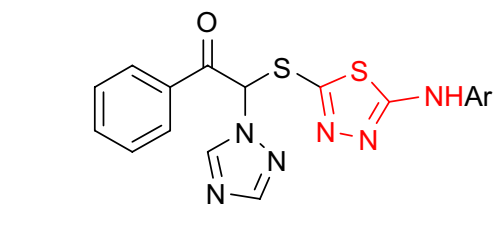

$$
\mathrm{Ar}=m-\mathrm{CH}_{3} \mathrm{C}_{6} \mathrm{H}_{4}, \mathrm{C}_{6} \mathrm{H}_{5}, m-\mathrm{ClC}_{6} \mathrm{H}_{4}, \mathrm{o}-\mathrm{CH}_{3} \mathrm{C}_{6} \mathrm{H}_{4}
$$

70

In addition, pyridazinone-substituted 1,3,4-thiadiazoles 71 synthesized by Zou et al ${ }^{127,128}$ were tested for in vivo antifungal activity against wheat leaf rust, Puccinia recondita, at a concentration of $0.001 \mathrm{M}$ solution in water/dimethylformamide. Some derivatives showed high inhibitory activity $(80 \%-90 \%)$ compared to the commercial fungicide, triadimefon $(100 \%$ inhibition). A quantitative SAR (QSAR) study showed that the increase in the hydrophobicity of $\mathrm{R}_{2}$ leads to an increased fungicidal activity $\left(m-\mathrm{CF}_{3}>o-\mathrm{F}>\mathrm{H}\right)$. Concerning the substituent $\mathrm{R}_{1}$, the best and consistent results were obtained in the cases of ortho substituents with inductive electron-donating properties. The preferred substituent for $\mathrm{R}_{1}$ was the 2,4-dimethyl group, as can be seen with compounds 71d and 71e.

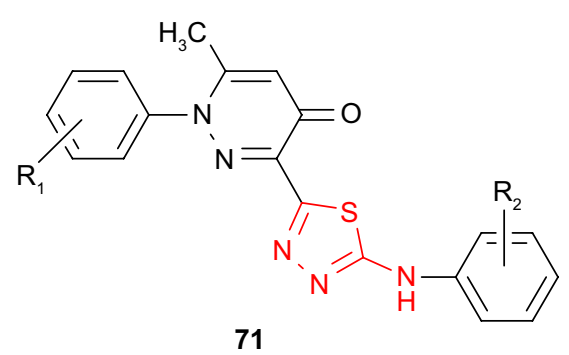

\begin{tabular}{llll}
\hline & $\mathbf{R}_{\mathbf{1}}$ & $\mathbf{R}_{\mathbf{2}}$ & Inhib (\%) \\
\hline a & $2,4-\mathrm{Cl}_{2}$ & $m-\mathrm{CF}_{3}$ & 90 \\
b & $2,4-\mathrm{Cl}_{2}$ & $o-\mathrm{F}$ & 80 \\
c & $2,4-\mathrm{Cl}_{2}$ & $\mathrm{H}$ & 20 \\
d & $2,4-\left(\mathrm{CH}_{3}\right)_{2}$ & $m-\mathrm{CF}_{3}$ & 90 \\
e & $2,4-\left(\mathrm{CH}_{3}\right)_{2}$ & $o-\mathrm{F}$ & 90 \\
\hline
\end{tabular}

\section{Conclusion}

Thiadiazole ring is present in compounds with various biological activities. Among the different isomers of thiadiazole, 1,3,4-thiadiazole derivatives are most studied due to broad spectrum of pharmacological activities. Although only a few pharmacological effects exhibited by 1,3,4-thiadiazole derivatives are currently clinically used (eg, antibacterial activity and carbonic anhydrase inhibiting activity), the substitution at thiadiazole ring is a challenging approach to obtain agents with improved potency and less toxicity.

The cytostatic properties of 2-amino-1,3,4-thiadiazole and the anti-trypanosomal properties of megazol are evidence of the biological potential of the 2-amino-1,3,4-thiadiazole moiety. Literature surveys report the antimicrobial activity of substituted 2-amino-1,3,4-thiadiazoles, making 2-amino-1,3,4-thiadiazole a unique template with significant utility in medicinal chemistry. Many 2-amino-1,3,4-thiadiazole derivatives can be considered as lead compounds for drug development. The SAR studies revealed that the antimicrobial activity is dependent on the nature of the substituents at the thiadiazole nucleus.

Although the antibacterial, antifungal and antitubercular properties are the main antimicrobial activities studied, other antimicrobial activities exhibited by 2 -amino-1,3,4thiadiazole derivatives are also explored. Many derivatives have shown good antimicrobial activities with good in vitro 
experimental results but deficient in vivo experimental data, suggesting that the mechanism of action is not clear and further studies are needed.

\section{Disclosure}

The authors report no conflicts of interest in this work.

\section{References}

1. Wermuth CG, Ciapetti P, Giethlen B, Bazzini P. Bioisosterism. Comprehensive Medicinal Chemistry. Vol. 2. Taylor JB, Triggle DJ, editors. Amsterdam: Elsevier; 2007:649-711.

2. Holla BS, Poorjary KN, Rao BS, Shivananda MK. New bisaminomercaptotriazoles and bis-triazolothiadiazoles as possible anticancer agents. Eur J Med Chem. 2002;37:511-517.

3. Yousif E, Majeed A, Al-Sammarrae K, Salih N, Salimon J, Abdullah B. Metal complexes of Schiff base: preparation, characterization and antibacterial activity. Arabian J Chem. 2013;5(S2). doi: 10.1016/j. arabjc.2013.06.006.

4. Li Y, Geng J, Liu Y, Yu S, Zhao G. Thiadiazole - a promising structure in medicinal chemistry. ChemMedChem. 2013;8(1):27-41.

5. Wermuth CG, Aldous D, Raboisson P, Rognan D. The Practice of Medicinal Chemistry. 4th ed. London: Academic Press, Elsevier; 2015:196.

6. Hu Y, Li CY, Wang XM, Yang YH, Zhu HL. 1,3,4-Thiadiazole: synthesis, reactions and applications in medicinal, agricultural, and materials chemistry. Chem Rev. 2014;114(10):5572-5610.

7. Brown N. Bioisosteres in Medicinal Chemistry. Weinheim, Germany: Wiley-VCH Verlag and Co., KGaA; 2012.

8. Tripathy R, Ghose A, Singh J, et al. 1,2,3-Thiadiazole substituted pyrazolones as potent KDR/VEGFR-2 kinase inhibitors. Bioorg Med Chem Lett. 2007;17(6):1793-1798.

9. Wermuth CG. Are pyridazines privileged structures? Med Chem Commun. 2011;2:935-941.

10. Biziere K, Worms P, Kan JP, Mandel P, Garattini S, Roncucci R. Minaprine, a new drug with antidepressant properties. Drugs Exp Clin Res. 1985;11(12):831-840.

11. Ueno S, Bracamontes J, Zorumski C, Weiss DS, Steinbach JH. Bicuculline and gabazine are allosteric inhibitors of channel opening of the GABA A receptor. J Neurosci. 1997;17(2):625-634.

12. Senff-Ribeiro A, Echevarria A, Silva EF, Franco CRC, Veiga SS, Oliveira MBM. Cytotoxic effect of a new 1,3,4-thiadiazolium mesoionic compound (MI-D) on cell lines of human melanoma. Br J Cancer. 2004;91(2):297-304.

13. Fosbinder RJ, Walter LA. Sulfanilamido derivatives of heterocyclic amines. J Am Chem Soc. 1939;61(8):2032-2033.

14. Lott WA, Bergeim FH. 2-( $p$-Aminobenzenesulfonamido)-thia zole: a new chemo therapeutic agent. J Am Chem Soc. 1939;61: 3593-3594.

15. Tappi G. Heterocyclic derivatives of sulfanilamide. Recl Trav Chim. 1943;62:207-209.

16. Masaki O, Mifune A, Higashijima T, Nagato S. 1,3,4-Thiadiazole derivatives. Several reactions of aminothiadiazoles. J Pharm Soc Jpn. 1951; 71:481-484.

17. Frisk AR. Sulfanilamide derivatives, chemotherapeutic evaluation of $\mathrm{N}_{1}$-substituted sulfonamide. Acta Med Scand Suppl. 1943;142:1.

18. Beale JM, Block JH. Wilson and Gisvold's Textbook of Organic Medicinal and Pharmaceutical Chemistry. 12th ed. Philadelphia: Lippincott Williams and Wilkins, Wolters Kluwer; 2011:238.

19. Roblin RO, Clapp JW. Carbonic anhydrase inhibitor. J Am Chem Soc. 1950;72:4890.

20. Clapp JW, Roblin RO. US Patent 2554816. 1951; Chem Abstr. 1952; 46:3087.

21. Seldin D, Giebisch G. Diuretic Agents: Clinical Physiology and Pharmacology. San Diego: Academic Press; 1997:24.
22. Lemke TL, Williams DA, Roche VF, Zito SW. Foye's Principles of Medicinal Chemistry. 7th ed. Philadelphia: Lippincott Williams and Wilkins, Wolters Kluwer; 2013:735.

23. Medindex [homepage on the Internet]. Available from: http://medindex.am/glossary/index.php/term/UMLS.+CSP-HL7-ICD9CM-NCINDFRT-RXNORM, METHAZOLAMIDE.xhtml. Accessed March 7, 2017.

24. Olsen JJ, Sloboda A, Troy WP, et al. The carcinostatic activity of some 2-amino-1,3,4-thiadiazoles. J Am Chem Soc. 1955;77:6713-6714.

25. Berkelhammer G, Asato G. 2-Amino-5-(1-methyl-5-nitro-2imidazolyl)-1,3,4-thiadiazole: a new antimicrobial agent. Science. 1968;162(3858):1146.

26. Marie-Daragon A, Rouillard MC, Bouteille B, Bisser S, de Albuquerque C. An efficacy trial on Trypanosoma brucei of molecules permeating the blood-brain barrier and of megazol. Bull Soc Pathol Exot. 1994;87(5): 347-352.

27. Bouteille B, Marie-Daragon A, Chauviere G, de Albuquerque C, Enanga B. Effect of megazol on Trypanosoma brucei acute and subacute infections in Swiss mice. Acta Trop. 1995;60(2):73-80.

28. Nesslany F, Brugier S, Mouries MA, Le Curieux F, Marzin D. In vitro and in vivo chromosomal aberrations induced by megazol. Mutat Res. 2004;560(2):147-158.

29. Enanga B, Ariyanayagam MR, Stewart ML, Barrett MP. Activity of megazol, a trypanocidal nitroimidazole, is associated with DNA damage. Antimicrob Agents Chemother. 2003;47(10):3368-3370.

30. de Silva Carvalho A, Salomao K, de Castro SL, et al. Megazol and its bioisostere $4 H-1,2,4$-triazole: comparing the trypanocidal, cytotoxic and genotoxic activities and their in vitro and in silico interactions with the Trypanosoma brucei nitroreductase enzyme. Mem Inst Oswaldo Cruz. 2014;109(3):315-323.

31. Chauviere G, Bouteille B, Enanga B, et al. Synthesis and biological activity of nitro heterocycles analogous of megazol, a trypanocidal lead. J Med Chem. 2003;46(3):427-440.

32. Nishida M, Matsubara T, Murakawa T, Mine Y, Yokota Y, Kuwahara S. In vitro and in vivo evaluation of cefazolin, a new cephalosporin C derivative. Antimicrob Agents Chemother (Bethesda). 1969;9: 236-243.

33. Nishida M, Matsubara T, Murakawa T, Mine Y, Yokota Y. Cefazolin, a new semisynthetic cephalosporin antibiotic. II. In vitro and in vivo antimicrobial activity. J Antibiot (Tokyo). 1970;23(3):137-148.

34. Kusaba T. Safety and efficacy of cefazolin sodium in the management of bacterial infection and in surgical prophylaxis. Clin Med Insights Ther. 2009;1:1607-1615.

35. Saginur R, Croteau D, Bergeron MG. Comparative efficacy of teicoplanin and cefazolin for cardiac operation prophylaxis in 3027 patients. The ESPRIT Group. J Thorac Cardiovasc Surg. 2000;120(6): $1120-1130$.

36. Maki DG, Bohn MJ, Stolz SM, Kroncke GM, Acher CW, Myerowitz PD. Comparative study of cefazolin, cefamandole and vancomycin for surgical prophylaxis in cardiac and vascular operations. A doubleblind randomized trial. J Thorac Cardiovasc Surg. 1992;104(5): $1423-1434$.

37. Finkelstein R, Rabino G, Mashiah T, et al. Vancomycin versus cefazolin prophylaxis for cardiac surgery in the setting of a high prevalence of methicillin-resistant staphylococcal infections. J Thorac Cardiovasc Surg. 2002;123(2):326-332.

38. Bolon MK, Morlote M, Weber SG, Koplan B, Carmeli Y, Wright SB. Glycopeptides are no more effective than beta-lactam agents for prevention of surgical infection after cardiac surgery: a meta-analysis. Clin Infect Dis. 2004;38(10):1357-1363.

39. Amir M, Kumar A, Ali I, Khan SA. Synthesis of pharmaceutically important 1,3,4-thiadiazole and imidazolinone derivatives as antimicrobials. Indian J Chem. 2009;48B:1288-1293.

40. Desai K, Baxi AJ. Studies on 2-azetidinone: part VI synthesis and antimicrobial activity of 5-(2',4'-dichlorophenoxymethyl)-2-(4"-aryl3"-chloro-2"-azetidinone-1"-yl)-1,3,4-thiadiazole. Indian J Pharm Sci. 1992;54:183-188. 
41. Salimon J, Salih N, Hameed A, Ibraheem H, Yousif E. Synthesis and antibacterial activity of some new 1,3,4-oxadiazole and 1,3,4thiadiazole derivatives. $J$ Appl Sci Res. 2010;6(7):866-870.

42. Oruc EE, Rollas S, Kandemirli F, Shvets N, Dimoglo A. 1,3,4Thiadiazole derivatives. Synthesis, structure elucidation and structureantituberculosis activity relationship investigation. J Med Chem. 2004; 47(27):6760-6767.

43. Bonina L, Iannello D, Merendino R, Arena A, Mastroeni P. Tumordependent resistance of rat peritoneal macrophages to herpes simplex virus. Drugs Exp Clin Res. 1983;9:577-583.

44. Schenone S, Brullo C, Bruno O, et al. New 1,3,4-thiadiazole derivatives endowed with analgesic and anti-inflammatory activities. Bioorg Med Chem. 2006;14(6):1698-1705.

45. Clerici F, Pocar D, Guido M, Loche A, Perlini V, Brufani M. Synthesis of 2-amino-5-sulfanyl-1,3,4-thiadiazole derivatives and evaluation of their antidepressant and anxiolytic activity. $J$ Med Chem. 2001;44(6): 931-936.

46. Turner S, Myers M, Gadie B, et al. Antihypertensive thiadiazoles. 2. Vasodilator activity of some 2-aryl-5-guanidino-1,3,4-thiadiazoles. J Med Chem. 1988;31(5):907-913.

47. Labanauskas L, Kalcas V, Udrenaite E, Gaidelis P, Brukstus A, Dauksas A. Synthesis of 3-(3,4-dimethoxyphenyl)-1 H-1,2,4-triazole5-thiol and 2-amino-5-(3,4-dimethoxyphenyl)-1,3,4-thiadiazole derivatives exhibiting anti-inflammatory activity. Pharmazie. 2001;56(8): 617-619.

48. Pattan SR, Desai NS, Rabara PA, Bukitgar AA, Wakale VA. Synthesis and antimicrobial evaluation of some 1,3,4-thiadiazole derivatives. Indian J Pharm Ed Res. 2008;42(4):314-318.

49. Mazzone G, Pignatello R, Mazzone S, et al. Synthesis and local anesthetic activity of alkylaminoacyl derivatives of 2-amino-1,3,4thiadiazole. Farmaco. 1993;48(9):1207-1224.

50. Siddiqui A, Dai C, Mansoor U, Yang L, Vitharana L, Angeles A. Spirocondensed 1,3,4-thiadiazole derivatives for inhibiting KSP kinesin activity. WO 2009/052288.

51. Basso A, Liu M, Dai C, et al. SCH 2047069, a novel oral kinesin spindle protein inhibitor, shows single-agent antitumor activity and enhances the efficacy of chemotherapeutics. Mol Cancer Ther. 2010;9(11): 2993-3002.

52. Taha SS, Ahmad AA, Mawlood SI, Ali NO. Synthesis of some series of 2-amino-1,3,4-thiadiazole derivatives with their pathogenic bacterial activity. J Raparin Univ. 2017;4(11):63-78.

53. Liu G, Cogan DA, Ellman JA. Catalytic asymmetric synthesis of tertbutanesulfinamide. Application to the asymmetric synthesis of amines. J Am Chem Soc. 1997;119(41):9913-9914.

54. Kadi AA, Al-Abdullah ES, Shehata IA, Habib EE, Ibrahim TM, El-Emam AA. Synthesis, antimicrobial and anti-inflammatory activities of novel 5-(1-adamantyl)-1,3,4-thiadiazole derivatives. Eur J Med Chem. 2010;45(11):5006-5011.

55. Sharma PC, Sinhmar A, Sharma A, Rajak H, Pathak DP. Medicinal significance of benzothiazole scaffold: an insight view. J Enzyme Inhib Med Chem. 2013;28(2):240-266.

56. Othman AA, Kihel M, Amara S. 1,3,4-Oxadiazole, 1,3,4-thiadiazole and 1,2,4-triazole derivatives as potential antibacterial agents. Arabian J Chem. 2014. doi: 10.1016/j.arabjc.2014.09.003.

57. Johnson DS, Li JJ. The Art of Drug Synthesis. Hoboken, NJ: WileyInterscience, John Wiley and Sons, Inc; 2007:40-72.

58. Fernandez L, Breidenstein EB, Hancock RE. Creeping baselines and adaptive resistance to antibiotics. Drug Resist Updat. 2011;14(1):1-21.

59. Lemke TL, Williams DA, Roche VF, Zito SW. Foye's Principles of Medicinal Chemistry. 7th ed. Philadelphia: Lippincott Williams and Wilkins, Wolters Kluwer; 2013:1159.

60. World Health Organization [webpage on the Internet]. Available from: http://www.who.int/world-health-day/2011/en/. Accessed April 21, 2018.

61. Bhuva H, Sahu D, Shah BN, Modi DC, Patel MB. Biological profile of thiadiazole. Pharmacologyonline. 2011;1:528-543.

62. Upadhyay PK, Mishra P. Synthesis, antimicrobial and anticancer activities of 5-(4-substituted phenyl)-1,3,4-thiadiazole-2-amines. Rasayan J Chem. 2017;10(1):254-262.
63. Hussain S, Sharma J, Amir M. Synthesis and Antimicrobial activities of 1,2,4-triazole and 1,3,4-thiadiazole derivatives of 5-amino-2hydroxybenzoic acid. E-J Chem. 2008;5(4):963-968.

64. Kucukguzel SG, Kucukguzel I, Tatar E, et al. Synthesis of some novel heterocyclic compounds derived from diflunisal hydrazide as potential anti-infective and anti-inflammatory agents. Eur J Med Chem. 2007; 42(7):893-901

65. Kadi AA, El-Brolossy NR, Al-Deeb OA, Habib EE, Ibrahim TM, El-Emam AA. Synthesis, antimicrobial, and anti-inflammatory activities of novel 2-(1-adamantyl)-5-substituted-1,3,4-oxadiazoles and 2-(1adamantylamino)-5-substituted-1,3,4-thiadiazoles. Eur J Med Chem. 2007;42(2):235-242.

66. Pintilie O, Profire L, Sunel V, Popa M, Pui A. Synthesis and antimicrobial activity of some new 1,3,4-tiadiazole and 1,2,4-triazole compounds having a D,L-methionine moiety. Molecules. 2007;12(1):103-113.

67. Rad O, Tibor R, Duma M, et al. Synthesis and antimicrobial activity of some 5-mercapto-2-amino-1,3,4-thiadiazole derivative thioethers and Schiff bases. Stud UBB Chem. 2016;61(1):17-32.

68. Matysiak J, Malinski Z. 2-(2,4-Dihydroxyphenyl)-1,3,4-thiadiazole analogues: antifungal activity in vitro against Candida species. Russ $J$ Bioorg Chem. 2007;33(6):594-601.

69. Raj MM, Patel HV, Raj LM, Patel NK. Synthesis and biological evaluation of some new 1,3,4-thiadiazole derivatives for their antimicrobial activities. Int J Pharm Chem Biol Sci. 2013;3(3):814-819.

70. Shah H, Vashi S, Mehta S. Synthesis of 2,5-disubstituted-1,3,4-oxadiazole, 1,5-disubstituted-2-mercapto-1,3,4-triazole and 2,5-disubstituted1,3,4-thiadiazole as potential antimicrobial agents. Indian $J$ Chem. 1996;35B:111-115.

71. Nargund GVL, Reddy NRG, Hariprasad N. Synthesis and antibacterial activity of a series of 1-aryl-2-mercapto-5-[4-(acetamidophenoxy)methyl]1,3,4-thiazoles, thiadiazoles and 2-[4-acetamidophenoxy carbonyl]3,4,5trisubstituted pyrazoles. Indian J Chem. 1996;35B:499-502.

72. Sah P, Bidawat P, Seth M, Gharu CP. Synthesis of formazans from Mannich base of 5-(4-chlorophenylamino)-2-mercapto-1,3,4-thiadiazole as antimicrobial agents. Arabian J Chem. 2014;7:181-187.

73. Dogan HN, Duran A, Rollas S, Sener G, Uysal MK, Gulen D. Synthesis of new 2,5-disubstituted-1,3,4-thiadiazoles and preliminary evaluation of anticonvulsant and antimicrobial activities. Bioorg Med Chem. 2002;10(9):2893-2898.

74. Farshori NN, Banday MR, Ahmad A, Khan AU, Rauf A. Synthesis, characterization and in vitro antimicrobial activities of 5-alkenyl/ hydroxyalkenyl-2-phenylamine-1,3,4-oxadiazoles and thiadiazoles. Bioorg Med Chem Lett. 2010;20(6):1933-1938.

75. Barboiu M, Cimpoesu M, Guran C, Supuran CT. 1,3,4-Thiadiazole derivatives. Part 9. Synthesis and biological activity of metal complexes of 5-(2-aminoethyl)-2-amino-1,3,4-thiadiazole. Met Based Drugs. 1996; 3(5):227-232.

76. Obaleye JA, Adediji JF, Adebayo MA. Synthesis and biological activities on metal complexes of 2,5-diamino-1,3,4-thiadiazole derived from semicarbazide hydrochloride. Molecules. 2011;16(7):5861-5874.

77. Ashutosh B, Ankur J, Kumar NR, et al. Synthesis, characterization and antimicrobial activity of azol substituted derivatives. Int J Pharm Sci Drug Res. 2009;1(3):207-210.

78. Rezki N, Al-Yahyawi AM, Bardaweel SK, Al-Blewi FF, Aouad MR. Synthesis of novel 2,5-disubstituted-1,3,4-thiadiazoles clubbed 1,2,4triazole, 1,3,4-thiadiazole, 1,3,4-oxadiazole and/or Schiff base as potent antimicrobial and antiproliferative agents. Molecules. 2015; 20(9):16048-16067.

79. He Y-W, Cao L-H, Zhang J-B, Wang D-Z, Aisa HA. Synthesis and bioactivity of 5-(1-aryl-1H-tetrazol-5-ylsulfanylmethyl)-N-xylopyranosyl-1,3,4-oxa(thia)diazol-2-amines. Carbohydr Res. 2011;346(5):551-559.

80. Sherman WR. 5-Nitro-2-furyl-substituted 1,3,4-oxadiazoles, 1,3,4thiadiazoles and 1,3,5-triazines. J Org Chem. 1961;26(1):88-95.

81. Demirbas N, Karaoglu SA, Demirbas A, Sancak K. Synthesis and antimicrobial activities of some new 1-(5-phenylamino-[1,3,4]thiadiazol2-yl)methyl-5-oxo-[1,2,4]-triazole and 1-(4-phenyl-5-thioxo-[1,2,4] triazol-3-yl)methyl-5-oxo-[1,2,4]triazole derivatives. Eur J Med Chem. 2004;39(9):793-804. 
82. Bektas H, Demirbas A, Demirbas N, Bayrak H, Karaoglu SA. Synthesis and antimicrobial activities of some new biheterocyclic compounds containing 1,2,4-triazol-3-one and 1,3,4-thiadiazole moieties. Turk $J$ Chem. 2010;34:517-527.

83. Demirbas A, Sahin D, Demirbas N, Karaoglu SA. Synthesis of some new 1,3,4-thiadiazol-2-ylmethyl-1,2,4-triazole derivatives and investigation of their antimicrobial activities. Eur J Med Chem. 2009; 44(7):2896-2903.

84. Bekhit AA, Ashour HMA, Ghany YSA, Bekhit AEA, Baraka A. Synthesis and biological evaluation of some thiazolyl and thiadiazolyl derivatives of $1 H$-pyrazole as anti-inflammatory antimicrobial agents. Eur J Med Chem. 2008;43(3):456-463.

85. Zamani K, Faghihi K, Tofighi T, Shariatzadeh MR. Synthesis and antimicrobial activity of some pyridyl and naphthyl substituted 1,2,4-triazole and 1,3,4-thiadiazole derivatives. Turk J Chem. 2004;28:95-100.

86. Zamani K, Faghihi K, Mehranjani MS. Synthesis of some new 2,5disubstituted 1,3,4-thiadiazoles containing isomeric pyridyl as potent antimicrobial agents. Pol J Pharmacol. 2003;55(6):1111-1117.

87. Szulczyk D, Tomaszewski P, Jozwiak M, et al. Synthesis and biological activities of ethyl 2-(2-pyridylacetate) derivatives containing thiourea, 1,2,4-triazole, thiadiazole and oxadiazole moieties. Molecules. 2017;22(3):409.

88. Patil RL, Mandhare NP, Bondge PS, Munde BS, Mane AR. Synthesis and antimicrobial activity of new pyrimidine incorporated $1,3,4$ thiadiazoles. Indian J Heterocycl Chem. 2003;12:245-248.

89. Andrews B, Komathi K, Mohan S. Synthesis and comparing the antibacterial activities of pyrimidine derivatives. JChem Soc. 2017;129(3): 335-341.

90. Klip NT, Capan G, Gursoy A, Uzun M, Satana D. Synthesis, structure and antifungal evaluation of some novel 1,2,4-triazolylmercaptoacetyl thiosemicarbazide and 1,2,4-triazolylmercaptomethyl-1,3,4-thiadiazole analogs. J Enzyme Inhib Med Chem. 2010;25(1):126-131.

91. Onkol T, Dogruer DS, Uzun L, Adak S, Ozkan S, Sahin MF. Synthesis and antimicrobial activity of new 1,2,4-triazole and 1,3,4-thiadiazole derivatives. J Enzyme Inhib Med Chem. 2008;23(2):277-284.

92. Tehranchian S, Akbarzadeh T, Fazeli MR, Jamalifar H, Shafiee A. Synthesis and antibacterial activity of 1-[1,2,4-triazol-3-yl] and 1-[1,3,4-thiadiazol-2-yl]-3-methylthio-6,7-dihydro-benzo[c]thiophen4(5H)ones. Bioorg Med Chem Lett. 2005;15(4):1023-1025.

93. Siddiqui N, Alam MS. 5-(1H-indol-3-ylmethyl)-N-(substituted phenyl)-1,3,4-thiadiazol-2-amine derivatives: synthesis and biological screening. Biosci Biotech Res Asia. 2009;6(1):261-264.

94. Siddiqui N, Ahuja P, Ahsan W, Pandeya SN, Alam MS. Thiadiazoles: progress report on biological activities. J Chem Pharm Res. 2009 1(1):19-30.

95. Vasoya SL, Paghdar DJ, Chovatia PT, Joshi HS. Synthesis of some new thiosemicarbazide and 1,3,4-thiadiazole heterocycles bearing benzo[b]thiophene nucleus as a potent antitubercular and antimicrobial agents. J Sci I R Iran. 2005;16(1):33-36.

96. Aly AA, El-Sayed R. Synthesis and biological activity of new 1,3,4thiadiazole derivatives. Chem Pap. 2006;60(1):56-60.

97. Thaker KM, Joshi HS. Synthesis and pharmacological evaluation of 2-(3',5'-dichlorobenzo[b]thiophen-2'-yl)-5-arylamino-1,3,4thiadiazoles. Indian J Chem. 2005;44B:410-412.

98. Ahmad T, Singh AK, Jaiswal N, Singh D. Synthesis and pharmacological activity of 1,3,4-thiadiazole derivatives: a review. Int Res $J$ Pharm. 2012;3(3):70-82.

99. Hegde VS, Kolavi GD, Lamani RS, Khazi IAM. Dimethyldithioimidocarbonates-mediated heterocyclizations: synthesis of imidazolidines and benzheterocycles as potent antitubercular agents. Phosphorus Sulfur Silicon. 2007;182(4):911-920.

100. Yousif E, Hameed A, Kamil A, Farina Y, Asaad N, Graisa A. Synthesis of new polymers derived from poly(vinyl chloride) and study their biological evaluation. Aust J Basic Appl Sci. 2009;3(3):1786-1794.

101. Patel D, Singh A. Synthesis, characterization and antimicrobial activity of metal chelates of 5-[4-chlorophenyl $(1,3,4)$ thiadiazol-2ylaminomethylene]-8-hydroxy quinoline. E-J Chem. 2009;6(4): 1017-1022.
102. Guzeldemirci NU, Kucukbasmaci O. Synthesis and antimicrobial activity evaluation of new 1,2,4-triazoles and 1,3,4-thiadiazoles bearing imidazo[2,1-b]thiazole moiety. Eur J Med Chem. 2010;45(1): 63-68.

103. Shelke S, Mhaske G, Gadakh S, Gill C. Green synthesis and biological evaluation of some novel azoles as antimicrobial agents. Bioorg Med Chem Lett. 2010;20(24):7200-7204.

104. Rostom SAF, El-Ashmawy IM, Abd El Razik HA, Badr MH, Ashour HMA. Design and synthesis of some thiazolyl and thiadiazolyl derivatives of antipyrine as potential non-acidic anti-inflammatory, analgesic and antimicrobial agents. Bioorg Med Chem. 2009;17(2):882-895.

105. Bayrak H, Demirbas A, Demirbas N, Karaoglu SA. Cyclization of some carbothioamide derivatives containing antipyrine and triazole moieties and investigation of their antimicrobial activities. Eur J Med Chem. 2010;45(11):4726-4732.

106. Camoutsis C, Geronikaki A, Ciric A, Sokovic M, Zoumpoulakis P, Zervou M. Sulfonamide-1,2,4-thiadiazole derivatives as antifungal and antibacterial agents: synthesis, biological evaluation, lipophilicity and conformational studies. Chem Pharm Bull. 2010;58(2):160-167.

107. Serban G, Suciu A, Coman M, Curea E. Synthesis and physicalchemical study of some 3-(5-arylamino-1,3,4-thiadiazol-2-yl)coumarins. Farmacia. 2002;50(6):50-54.

108. Serban G, Coman M, Curea E. Synthesis of some heterocyclic nitrocoumarins by Knoevenagel condensation. Farmacia. 2005;53(1) 78-84.

109. Serban G, Matinca D, Bradea O, Gherman L, Coman M, Curea E. The study of the biological activity of some heterocyclic coumarins. Farmacia. 2005;53(2):91-99.

110. Koga H, Itoh A, Murayama S, Suzue S, Irikura T. Structureactivity relationships of antibacterial 6,7- and 7,8-disubstituted 1-alkyl-1,4-dihydro-4-oxoquinoline-3-carboxylic acids. J Med Chem. 1980;23(12):1358-1363.

111. Ginsburg AS, Grosset JH, Bishai WR. Fluoroquinolones, tuberculosis and resistance. Lancet Infect Dis. 2003;3(7):432-442.

112. Talath S, Gadad AK. Synthesis, antibacterial and antitubercular activities of some 7-[4-(5-amino-[1,3,4]thiadiazole-2-sulfonyl)-piperazin1-yl]fluoroquinolonic derivatives. Eur J Med Chem. 2006;41(8): 918-924.

113. Foroumadi A, Mansouri S, Kiani Z, Rahmani A. Synthesis and in vitro antibacterial evaluation of $\mathrm{N}$-[5-(5-nitro-2-thienyl)-1,3,4-thiadiazole-2yl] piperazinyl quinolones. Eur J Med Chem. 2003;38(9):851-854.

114. Nieto MJ, Alovero FL, Manzo RH, Mazzieri MR. Benzenesulfonamide analogs of fluoroquinolones. Antibacterial activity and QSAR studies. Eur J Med Chem. 2005;40(4):361-369.

115. Neu HC, Gootz TD. Chapter 11 Antimicrobial Chemotherapy. In: Baron S, editor. Medical Microbiology. 4th ed. Galveston, Texas: University of Texas Medical Branch; 1996:4.

116. Hadizadeh F, Vosooghi R. Synthesis of $\alpha$-[5-(5-amino-1,3,4-thiadiazol2-yl)-2-imidazolylthio]-acetic acids. J Heterocycl Chem. 2008;45(5) 1477-1479.

117. Karakus S, Rollas S. Synthesis and antituberculosis activity of new $N$-phenyl- $N^{\prime}$-[4-(5-alkyl/arylamino-1,3,4-thiadiazole-2-yl)phenyl] thioureas. Farmaco. 2002;57(7):577-581.

118. Sathe BS, Jayachandran E, Chaugule D, Jagtap VA. Synthesis of novel fluorobenzothiazole linked thiadiazole compounds: as possible anti-tubercular agents. J Pharm Res. 2011;4(4):1031-1032.

119. Solak N, Rollas S. Synthesis and antituberculosis activity of 2-(aryl/ alkylamino)-5-(4-aminophenyl)-1,3,4-thiadiazoles and their Schiff bases. ARKIVOC. 2006;2006(12):173-181.

120. Patole J, Shingnapurkar D, Padhye S, Ratledge C. Schiff base conjugates of $p$-aminosalicylic acid as antimycobacterial agents. Bioorg Med Chem Lett. 2006;16(6):1514-1517.

121. Tatar E, Kucukguzel SG, Karakus S, et al. Synthesis and biological evaluation of some new 1,3,4-thiadiazole and 1,2,4-triazole derivatives from $L$-methionine as antituberculosis and antiviral agents. Marmara Pharm J. 2015;19(2):88-102.

122. Heubach G, Sachse B, Buerstell H. US Patent No. 4239 525, 1980. Chem Abstr. 1980;92:181200h. 
123. Asif M. A review on pharmacological potentials of various substituted thiadiazole analogs. Int J Cur Res Appl Chem Chem Eng. 2016;2(2):1-26.

124. Zong G, Zhao H, Jiang R, et al. Design, synthesis and bioactivity of novel glycosylthiadiazole derivatives. Molecules. 2014;19(6):7832-7849.

125. Yadav LS, Zaidi MGH, Singh BN. Synthesis and fungicidal evaluation of some 1,3,4-thiadiazoles against $P$. oryzae and $R$. solani. Asian $J$ Chem. 2003;15(3):1805-1807.

126. Chu CH, Hui XP, Xu PF, Zhang ZY, Li ZC, Liao RA. Synthesis and antifungal activities of $\omega$-(5-arylamino-1,3,4-thiadiazol-2-thio-)$\omega-(1 H-1,2,4-$ triazol-1-yl)acetophenones. Indian J Chem. 2002;41B: 2436-2438.
127. Zou XJ, Lai LH, Jin GY, Zhang ZX. Synthesis, fungicidal activity, and 3D-QSAR of pyridazinone-substituted 1,3,4-oxadiazoles and 1,3,4-thiadiazoles. J Agric Food Chem. 2002;50(13):3757-3760.

128. Zou XJ, Jin GY, Zhang ZX. Synthesis, fungicidal activity, and QSAR of pyridazinonethiadiazoles. J Agric Food Chem. 2002;50(6): 1451-1454.

\section{Publish your work in this journal}

Drug Design, Development and Therapy is an international, peerreviewed open-access journal that spans the spectrum of drug design and development through to clinical applications. Clinical outcomes, patient safety, and programs for the development and effective, safe, and sustained use of medicines are the features of the journal, which has also been accepted for indexing on PubMed Central. The manuscript management system is completely online and includes a very quick and fair peer-review system, which is all easy to use. Visit http://www.dovepress.com/testimonials.php to read real quotes from published authors.

Submit your manuscript here: http://www.dovepress.com/drug-design-development-and-therapy-journal 